\title{
MicroRNA-195 Protects Against Dementia Induced by Chronic Brain Hypoperfusion via Its Anti-Amyloidogenic Effect in Rats
}

\author{
Jing Ai, ${ }^{1 \star}$ Li-Hua Sun, ${ }^{1 *}$ Hui Che, ${ }^{1 \star}$ Rong Zhang, ${ }^{1}$ Tian-Zhu Zhang, ${ }^{1}$ Wan-Chen Wu, ${ }^{1}$ Xiao-Lin Su, ${ }^{1}$ Xin Chen,${ }^{1,2}$ \\ Guang Yang, ${ }^{2}$ Kang Li, ${ }^{3}$ Ning Wang, ${ }^{1}$ Tao Ban,,${ }^{1}$ Ya-Nan Bao, ${ }^{1}$ Fei Guo, ${ }^{1}$ Hui-Fang Niu, ${ }^{1}$ Yu-Lan Zhu, ${ }^{4}$ Xiu-Ying Zhu, ${ }^{5}$ \\ Shi-Guang Zhao, ${ }^{2}$ and Bao-Feng Yang ${ }^{1}$ \\ ${ }^{1}$ Department of Pharmacology, Harbin Medical University, Harbin, Heilongjiang Province, People's Republic of China, 150081; ${ }^{2}$ Department of \\ Neurosurgery, The First Affiliated Hospital of Harbin Medical University, Harbin, Heilongjiang Province, People's Republic of China,150001; ${ }^{3}$ The \\ Department of Biostatistics, Harbin Medical University, Harbin, Heilongjiang Province, People's Republic of China, 150081; and ${ }^{4}$ Department of Neurology \\ and ${ }^{5}$ Department of Gerontology, The Second Affiliated Hospital of Harbin Medical University, Harbin, Heilongiiang Province, People's Republic of China, \\ 150086
}

Previous studies have demonstrated that chronic brain hypoperfusion $(\mathrm{CBH})$ causes $\mathrm{A} \beta$ aggregation by upregulating expression of amyloid precursor protein (APP) and $\beta$-site APP cleaving enzyme 1 (BACE1) protein, which is accompanied by cognitive impairment, but the mechanisms are not fully understood. In this study, we evaluated the effect of microRNA on memory impairment in rats induced by $\mathrm{CBH}$. We show here that $\mathrm{CBH}$ generated by bilateral common carotid artery occlusion (2V0) significantly decreased the learning and memory ability in rats, as assessed by Morris water maze, and upregulated expression of APP and BACE1 proteins in the hippocampus and cortex of rats, as evaluated by Western blot and immunofluorescence. In reciprocal, qRT-PCR analysis showed that microRNA-195 ( $m i R-195)$ was downregulated in both the hippocampus and cortex of rats following $\mathrm{CBH}$, and in the plasma of dementia patients. APP and BACE1 proteins were downregulated by $m i R-195$ overexpression, upregulated by $m i R-195$ inhibition, and unchanged by binding-site mutation or miR-masks, indicating that APP and BACE1 are two potential targets for $m i R-195$. Knockdown of endogenous $m i R-195$ by lentiviral vector-mediated overexpression of its antisense molecule (lenti-pre-AMO-miR-195) elicited dementia in rats, whereas overexpression of $m i R-195$ using lenti-pre-miR-195 reduced dementia vulnerability triggered by $2 \mathrm{VO}$. Additionally, chromatin immunoprecipitation analysis showed that $\mathrm{NF} \kappa \mathrm{B}$ was bound to the promoter region of $m i R-195$ and inhibited its expression. We conclude that miR-195 may play a key role in determining dementia susceptibility in 2V0 rats by regulating APP and BACE1 expression at the post-transcriptional level, and exogenous complement of miR-195 may be a potentially valuable anti-dementia approach.

\section{Introduction}

The incidence of clinical dementia throughout the world is increasing as the population ages. Alzheimer's disease (AD) accounts for $\sim 60 \%$ and vascular dementia (VaD) accounts for $\sim 30 \%$ of the prevalence. Though they are classified as different subtypes, $\mathrm{AD}$ and $\mathrm{VaD}$ share common risk factors, indicating that

\footnotetext{
Received April 25, 2012; revised Jan. 12, 2013; accepted Jan. 15, 2013

Author contributions: J.A. and B.-F.Y. designed research; J.A., L.-H.S., H.C., R.Z., T.-Z.Z., W.-C.W., X.-L.S., X.C., G.Y., N.W., T.B., Y.-N.B., F.G., H.-F.N., Y.-L.Z., X.-Y.Z., and S.-G.Z. performed research; J.A., L.-H.S., H.C., and K.L. analyzed data; J.A. and L.-H.S. wrote the paper.

This work was supported by Natural Science Foundation of China (81271207, 81070882, and 81000499) and Creative Research Groups of the National Natural Science Foundation of China (81121003). We thank Dr. Hai-Yan Zhang, from Shanghai Institute of Materia Medica (China), for her suggestion for the discussion and technical guidance; Dr. Fang Xie, from Harbin Medical University, for her excellent job of drawing; Dr. Jeff Hatcher, from the University of Central Florida College of Medicine, for his kindly English edition.

*J.A., L.-H.S., and H.C. contributed equally to this paper.

The authors declare no competing financial interests.

Correspondence should be addressed to either Jing Ai or Bao-Feng Yang, Department of Pharmacology, Harbin Medical University, №.157 Baojian Road, Nangang District, Harbin, Heilongjiang Province, China, 150081, E-mail: a.z.hrbmu@gmail.com or yangbf@ems.hrbmu.edu.cn.

DOI:10.1523/JNEUROSCI.1997-12.2013

Copyright $\odot 2013$ the authors $\quad 0270-6474 / 13 / 333989-13 \$ 15.00 / 0$
}

their etiology is somehow related (Cole and Vassar, 2009). Currently, chronic brain hypoperfusion $(\mathrm{CBH})$ is considered as a preclinical condition of mild cognitive impairment and is thought to precede dementia (Ruitenberg et al., 2005; Gorelick et al., 2011). However, how CBH produces dementia is largely unknown. Previous studies have demonstrated that $\mathrm{CBH}$ could induce cognitive impairment accompanied by amyloid- $\beta$ (A $\beta)$ aggregation (Kitaguchi et al., 2009; Zhiyou et al., 2009), but the mechanisms are not fully understood.

Recent studies reported that microRNAs (miRNAs) can regulate amyloid precursor protein (APP) and $\beta$-site APP cleaving enzyme 1 (BACE1) expressions. miR-298, miR-328 (Boissonneault et al., 2009), miR-107 (Wang et al., 2008), miR-29a/b-1, miR-9 (Hébert et al., 2008), and $m i R-29 c$ (Zong et al., 2011) were found to target the BACE1 gene and to be decreased in their expression in AD transgenic animals or AD patients. APP was identified as a target for $m i R-16$, the expression of which is decreased in senescenceaccelerated transgenic mice (Liu et al., 2012). In addition, $m i R$ 17-5p, miR-20a (Hébert et al., 2009), and miR-101 (Long and Lahiri, 2011) were reported to regulate the expression of APP in 
human cell lines, and miR-124 modulated APP mRNA alternative splicing (Smith et al., 2011). Though these studies revealed the participation of miRNAs in the process of $\mathrm{AD}$ pathology, some important issues related to this novel mechanism remained unclear. Whether the downregulated miRNAs identified in AD transgenic mice models or $\mathrm{AD}$ patients were indeed caused by $\mathrm{AD}$ is still unresolved. What factors cause downregulation of these miRNAs in $\mathrm{AD}$ transgenic mice models and $\mathrm{AD}$ patients? What pathophysiological roles do deregulated miRNAs play? More of an issue of concern is that $\mathrm{CBH}$ not only is a common risk factor of $\mathrm{AD}$ and $\mathrm{VaD}$, but is also accompanied by APP/BACE1 upregulation (Bennett et al., 2000; Cole and Vassar, 2009). Understanding how $\mathrm{CBH}$ produces dementia through upregulation of APP and BACE1 by miRNAs is particularly interesting.

By computational analysis of miRNAs that have the potential to target both APP and BACE1 3' untranslated region (3'UTRs) using Targetscan and Pictar database, we identified that the $m i R$ 195/15b/16 miRNA family members are miRNAs that carry their binding sites in the $3^{\prime}$ UTR of both APP and BACE1 genes. Aberrant expressions of $m i R-15 b$ and $m i R-16$ have been reported to play an important role in cancers, cardiovascular disease, and AD progression (Finnerty et al., 2010; Wang et al., 2011; Liu et al., 2012). Downregulation of $m i R-195$ expression has been observed in various types of cancers (Soon et al., 2009; Xu et al., 2009; Ujifuku et al., 2010), in which $m i R-195$ acts in a tumorsuppressor role. More importantly, a previous study reported that $m i R-195$ regulates BDNF and alters the expression of downstream GABAergic transcripts in schizophrenia (Mellios et al., 2008), suggesting potential effects of $m i R-195$ in CNS. However, the possible roles of $m i R-195$ in dementia have not been studied. We hypothesized that $\mathrm{CBH}$ can develop into dementia through inhibition of $m i R-195 / 15 b / 16$ expression, which in turn upregulates the expression of both APP and BACE1 proteins at the posttranscriptional levels.

\section{Materials and Methods}

Animals. Male Sprague Dawley (SD) rats (weight 220-260 g, obtained from the Animal Center of the Second Affiliated Hospital of Harbin Medical University, Harbin, Heilongjiang Province, China) were housed at $23 \pm 1{ }^{\circ} \mathrm{C}$ with $55 \pm 5 \%$ of humidity and maintained on $12 \mathrm{~h}$ dark/light artificial cycle (lights on at 7:00 A.M.) with food and water available $a d$ libitum. Rats for creating permanent, bilateral common carotid artery occlusion (2VO) and stereotaxic injection of the lentiviral vectors were anesthetized with chloral hydrate $(300 \mathrm{mg} / \mathrm{kg})$ by intraperitoneal injection and maintained by administrating $0.5-1.0 \%$ isoflurane. The depth of anesthesia was monitored by detecting reflexes, heart rate, and respiratory rate. Samples for quantitative real-time (qRT)-PCR, Western blot assay, immunofluorescence staining, and ELISA analysis were obtained from the hippocampus and/or cortex of rats after they had been anesthetized with chloral hydrate $(500 \mathrm{mg} / \mathrm{kg}$, i.p.) followed by confirmation of death by exsanguination. Tissues for primary neuron culturing were from neonatal SD rats after administration of $20 \%$ isoflurane and confirmation of death by cervical dislocation. All animal procedures were approved by the Institutional Animal Care and Use Committee at Harbin Medical University (No. HMUIRB-2008-06) and the Institute of Laboratory Animal Science of China (A5655-01). All procedures were conformed to the Directive 2010/63/EU of the European Parliament.

Permanent, $2 \mathrm{VO}$ in the rat. The method for preparation of $2 \mathrm{VO}$ rat was according to the study reported by Kumaran et al., (2008). Briefly, after being anesthetized, the bilateral common carotid arteries of rats were exposed via a midline ventral incision, carefully separated from the vagal nerves, and permanently ligated with $5-0$ silk suture. The wounds were then sutured and rats were allowed to recover from anesthesia before being returned back to their cages. The extent of cerebral ischemia was evaluated at 1 and 8 weeks post $2 \mathrm{VO}$. Briefly, the brains of rats were immediately removed, cut into $2 \mathrm{~mm}$ sections, then immersed sequentially into a phosphate-buffered 2\% 2,3.5-triphenyltetrazolium chloride (TTC) solution at $37^{\circ} \mathrm{C}$ for $30 \mathrm{~min}$, and then fixed in phosphate-buffered $4 \%$ paraformaldehyde (PFA) solution at $4^{\circ} \mathrm{C}$.

Morris water maze. The Morris water maze (MWM) consisted of a black circular pool of $2.0 \mathrm{~m}$ diameter, filled with opaque water $\left(25 \pm 1^{\circ} \mathrm{C}\right)$ via addition of black food pigment. A submerged escape platform $(20 \mathrm{~cm}$ diameter platform, top surface $2.0 \mathrm{~cm}$ below water level) was located in the center of the first quadrant. Before training, the pupillary light reflex of all rats was tested and rats with impaired pupillary light reflex were excluded from the experiment to avoid the influence of the animal's vision on the test (Stevens et al., 2002). For cued training (three trials per day for $5 \mathrm{~d}$ ), the rats were released into the water facing the side walls, and each rat was allowed $120 \mathrm{~s}$ to find the platform, otherwise, they were guided to the platform and permitted to rest for at least $20 \mathrm{~s}$. After the last cued trial of day 5 , the platform was removed from the pool and each rat received one $120 \mathrm{~s}$ swim probe trial on day 6 . Escape latency (s), length of swim path $(\mathrm{cm})$, swim speed $(\mathrm{cm} / \mathrm{s})$, the times of crossing platform, and the percentage of swimming distance in target quadrant in total distances of the pool were monitored using an online DigBehav-Morris water maze Video Analysis System (Mobile Datum Software Technology).

Human blood sample preparation. Patients (average age: $82 \pm 4$ years old) from the First and Second Affiliated Hospital of Harbin Medical University diagnosed with $\mathrm{VaD}$ were recruited in the hospital based on the criteria of the National Institute of Neurological and Communicative Disorders (Sarazin et al., 2012). Written consent was obtained from all subjects, and the study protocol was approved by the Ethics Committee of Harbin Medical University.

For miRNA and $A \beta$ quantification, whole blood samples $(3 \mathrm{ml}$ per patient) were collected from subjects via a direct venous puncture into a vacuum blood collection tube with sodium citrate. Whole blood samples of $0.5 \mathrm{ml}$ were carefully transferred into an RNase-free tube for extraction of RNA. The remnant of the blood sample was used for ELISA analysis.

Sandwich ELISA analysis. Preparation of samples used for ELISA analysis has been described previously (Lazarov et al., 2005; Bales et al., 2009; Meilandt et al., 2009). Frozen tissue from unilateral hippocampus samples were homogenized in Tris-buffered saline (TBS) containing protease inhibitors at $4^{\circ} \mathrm{C}$ for $30 \mathrm{~min}$. Extracts were centrifuged at $100,000 \times g$ for $1 \mathrm{~h}$ at $4^{\circ} \mathrm{C}$. The supernatant representing the TBS-soluble fraction $(\mathrm{A} \beta$ TBS) was collected. The resultant pellet was resuspended and sonicated in radioimmunoprecipitation assay (RIPA), and incubated at room temperature for $90 \mathrm{~min}$. The RIPA-solubilized homogenates were centrifuged at $100,000 \times g$ for $1 \mathrm{~h}$ at $4^{\circ} \mathrm{C}$. The supernatant representing the RIPA-soluble fraction (A $\beta$-RIPA) was collected. The insoluble pellets were resuspended in $5 \mathrm{M}$ guanidine $\mathrm{HCl}, \mathrm{pH} 8.0$, sonicated for $15 \mathrm{~s}$, and incubated at $4^{\circ} \mathrm{C}$ for $90 \mathrm{~min}$. The extracts were used to evaluate the insoluble $\mathrm{A} \beta$. The level of insoluble or soluble $\mathrm{A} \beta$ was captured by monoclonal antibody BNT77, recognized by horseradish peroxidaseconjugated antibody specific for $A \beta_{40}$ (BA27) and $A \beta_{42}$ (BC05), quantified by using commercial $\mathrm{A} \beta_{1-42}$ and $\mathrm{A} \beta_{1-40}$ Kits (Wako Pure Chemical; catalog \#292-64501, \#294-64701), and finally analyzed according to the instructions of the kits.

For plasma $\mathrm{A} \beta$ level detection, briefly, blood collected in a vacuum blood collection tube with sodium citrate was centrifuged at $5000 \times \mathrm{g}$, $4^{\circ} \mathrm{C}$ for 5 min to separate plasma from whole blood. A total of $0.2 \mathrm{ml}$ plasma was diluted with $0.6 \mathrm{ml}$ standard diluent. Captured $\mathrm{A} \beta$ was quantified and analyzed according to the instruction of the kits (Wako Pure Chemical; catalog \#292-64501, \#294-64701).

Primary hippocampal and cortical neuron cultures. The hippocampal and cortical regions were removed from postnatal day 0 rat pups. After tissues were dissected and triturated, they were plated onto cell plates precoated with $10 \mu \mathrm{g} / \mathrm{ml}$ poly-D-lysine (Sigma) and cultured in culture media containing neurobasal medium (Invitrogen) with 2\% B27 supplement (Invitrogen) and 10\% fetal bovine serum (FBS; HyClone). After $3 \mathrm{~d}$, the neurons were treated with $5 \mu \mathrm{M}$ cytosine arabinoside (Sigma) to inhibit astrocyte proliferation. For all experiments, the neurons were used $5-7 \mathrm{~d}$ after plating. 
Synthesis of miR-195, AMO-195, and other various oligonucleotides. miR-195 mimics (sense: 5' -UAGCAGCACAGAAAUAUUGGC-3'; antisense: $5^{\prime}$-CAAUAUUUCUGUGCUGCUAUU-3') and AMO-miR-195 (5'-GCCAAUAUUUCUGUGCUGCUA-3') were synthesized by Shanghai GenePharma. AMO-195 contains 2' -O-methyl modifications. In addition, a scrambled RNA was used as a negative control (NC) (sense: 5'-UUCUCCGAACGUGUCACGUAA-3' and antisense: $5^{\prime}$-ACGUGA CACGUUCGGAGAAUU- $3^{\prime}$ ). The BACE1 and APP-masking antisense oligodeoxynucleotides (ODNs) were synthesized by Shanghai Sangon Biological Engineering Technology and Service. BACE1 masking antisense-ODN-1 was 5'-AAGCAGCAACAUUUCCAACTC-3', which masks the binding sites of miR-195 located in position 266-272 of BACE1 3'UTR; BACE1 masking antisense-ODN-2 was 5'-AGCCAGAG CAGCCCCAGUGCA-3', which masks the binding sites of $m i R-195$ located in position 1795-1801 of BACE1 3' UTR; APP masking antisenseODN was $5^{\prime}$-AAGCAGCAAUCUGUACAGUAA-3', which masks the binding sites of $m i R-195$, located in position 562-568 of APP 3'UTR; five nucleotides or deoxynucleotides at both ends of the antisense molecules were locked by a methylene bridge connecting between the $2^{\prime}-O$ - and the $4^{\prime}$-C atoms.

Transfection procedures. Then $75 \mathrm{pmol} / \mathrm{ml}$ miR-195 and/or AMO-195, ODNs, or NC siRNAs were transfected into neonatal hippocampal and cortical neurons with X-treme GENE siRNA transfection reagent (cata$\log \# 04476093001$; Roche) according to the manufacturer's instructions. Forty-eight hours after transfection, cells were collected for total RNA isolation or protein purification.

Construction of lentivirus vectors. Using the BLOCK-iT pol II miR RNAi expression vector with the EmGFP kit from Invitrogen, three single-stranded DNA oligonucleotides were designed as follows: (1) premiR195 ("top strand" oligo: tgctgTAGCAGCACAGAAATATTGGCG TTTTGGCCACTGACTGACGCCAATATCTGTGCTGCTA) and its complementary chain ("bottom strand" oligo: cctgTAGCAGCACAGA TATTGGCGTCAGTCAGTGGCCAAAACGCCAATATTTCTGTGCTG CTAc); (2) pre-AMO-miR195 ("top strand” oligo: tgctgGCCAATATTT CTGTGCTGCTAGTTTTGGCCACTGACTGACTAGCAGCAGAAATA TTGGC) and its complementary sequence ("bottom strand" oligo: cctgG CCAATATTTCTGCTGCTAGTCAGTCAGTGGCCAAAACTAGCAGC ACAGAAATATTGGCc); and (3) negative control ("top strand" oligo: tgctgAAATGTACTGCGCGTGGAGACGTTTTGGCCACTGACTGA CGTCTCCACGCAGTACATTT) and its complementary sequence ("bottom strand" oligo: cctgAAATGTACTGCGTGGAGACGTCAGTC AGTGGCCAAAACGTCTCCACGCGCAGTACATTTc). We then cloned the double-stranded oligonucleotides generated by annealing the top and bottom strand oligos into the pcDNA6.2-GW/ \pm EmGFP-miR vector and transformed the ligated constructs into competent Escherichia coli. After the colony was purified and identified as the correct expression clone, the pre-miRNA expression cassette was transferred to the Gateway adapted destination vectors using Pol II promoters to form a new miRNA expression clone containing attR substrates. The vector was identified after analyzing the plasmid sequence (Invitrogen). The titers of lenti-pre$m i R-195$ and lenti-pre-AMO-miR-195 vectors used for experiments were $1.05 \times 10^{8}$ transducing $\mathrm{U} / \mathrm{ml}$ and $7.0 \times 10^{7}$ transducing $\mathrm{U} / \mathrm{ml}$, respectively. Virus suspensions were stored at $-80^{\circ} \mathrm{C}$ until use and were briefly centrifuged and kept on ice immediately before injection.

Stereotaxic injection of the lentiviral vectors. After anesthesia, rats were placed into a stereotaxic frame (RWB Life Science). Injection coordinates relative to the bregma were as follows: anteroposterior, $-4.52 \mathrm{~mm}$; mediolateral, $\pm 3.2 \mathrm{~mm}$; dorsoventral $-3.16 \mathrm{~mm}$ below the surface of dura using coordinates derived from the atlas of Paxinos and Watson (1997). Two microliters $(10,000 \mathrm{TU} / \mu \mathrm{l})$ lenti-pre-miR-195 and/or lenti-preAMO-miR-195 were injected into CA1 of hippocampus using a $5 \mu \mathrm{l}$ Hamilton syringe with a 33 gauge tip needle (Hamilton). The needle was then maintained in the place for another $2 \mathrm{~min}$ after injection and then withdrawn very slowly to prevent backflow of solution. The accuracy of injection sites was identified by the Evans blue (Sigma) stereotaxic injection directly into the hippocampus CA1 subfield.

Lipopolysaccharide treatments. Lipopolysaccharide (LPS), purchased from Sigma Chemical, was dissolved in neurobasal medium to create a $100 \mu \mathrm{g} / \mathrm{ml}$ stock solution and stored at $-20^{\circ} \mathrm{C}$. When the cells had been cultured $5 \mathrm{~d}$ in vitro, they were exposed to fresh culture media with or without $10 \mu \mathrm{g} / \mathrm{ml}$ of LPS for the time period to be indicated.

Dual Luciferase reporter assay. HEK293T cells (plated at 40-50\% confluence) were transfected with $20 \mu \mathrm{mol} / \mathrm{L} m i R-195$, AMO-195, or NC siRNAs as well as $0.5 \mu \mathrm{g}$ of psi-CHECK-2-target DNA (firefly luciferase vector) and $1 \mu$ l of blank plasmid using Lipofectamine 2000 (Invitrogen) transfection reagent according to the manufacturer's instructions. After $48 \mathrm{~h}$ of transfection, luciferase activities were measured with a dual luciferase reporter assay kit (catalog \#E1910; Promega) and luminometer (GloMax 20/20; Promega). Nucleotide-substitution mutagenesis was performed using direct oligomer synthesis for the 3'UTRs of APP, BACE1-binding site 1 and BACE1-binding site 2. All constructs were sequence verified.

Chromatin immunoprecipitation assay. Primary neurons were cultured as described above. The medium for the cultured neurons was replaced by fresh neurobasal medium with 2\% B27 and 10\% of FBS (HyClone) once every $3 \mathrm{~d}$. The $\mathrm{NF} \kappa \mathrm{B}$ protein expression was initially detected by Western blot with antibodies against p65 (ab7970; Abcam). Chromatin immunoprecipitation assay (ChIP) was performed with the imprint ChIP assay kit (catalog \#26156; Pierce Thermo Fisher Scientific) according to the manufacturer's instructions. The PCR primers ( $m i R-195 \mathrm{ChIP}$ Forward (F) primer 1: 5' -TGGGGTGAGGAATGTAGTGTTG-3', miR195 ChIP Reverse (R) primer 1: 5' -GGTCCCCTATTTTGAAAGGAGC3', miR-195 ChIP F2: 5' -CTTAGGTCCCTGCCTCTGTCG-3', miR-195 ChIP R2: 5' -GAACAACAAAATCGGGAACCAGC-3') were designed to amplify 296 and 201 bp fragments, respectively, from selected genomic regions, respectively. RT-PCR of genomic regions containing the putative NF $\kappa \mathrm{B}$-binding sites was performed in triplicate. Cycling parameters were $98^{\circ} \mathrm{C}$ for $5 \mathrm{~min}$, followed by 35 cycles of $98^{\circ} \mathrm{C}$ for $30 \mathrm{~s}, 55^{\circ} \mathrm{C}$ for $20 \mathrm{~s}$, $68^{\circ} \mathrm{C}$ for $20 \mathrm{~s}$, and $72^{\circ} \mathrm{C}$ for $5 \mathrm{~min}$. Amplification of the negative control construct, a 213 bp fragment spanning selected genomic regions, was performed with oligos 5'-CCAGCTCACGAGGGCCTCGG-3' and 5' CAGCCGCCCAGACCAAATGG-3'. The relative occupancy of the immunoprecipitated factor at a locus was estimated by using the comparative threshold method.

$q R T-P C R$. Total RNA was purified with the Trizol Reagent (Invitrogen), according to the manufacturer's instructions. MiR-195 level was quantified by the TaqMan MicroRNA Reverse Transcription Kit (catalog \#4366596, ABI; Roche) and TaqMan Gene Expression Master Mix (catalog \#4369016; Applied Biosystems). APP and BACE1 mRNA levels were quantified by the High Capacity cDNA Reverse Transcription Kit (cata$\log \# 4368814, \mathrm{ABI}$; Roche) and the TaqMan Gene Expression Master Mix (catalog \#4369016; Applied Biosystems). U6 or $\beta$-actin was used as an internal control. The TaqMan qRT-PCR probes and primers for $m i R-195$ (catalog \#4427975, ID: 000494), BACE1 (catalog \#4331182; ID: Rn00569988_m1), APP (catalog \#448892; ID: Rn00570673_ml), U6 (catalog \#4427975; ID: 001973), and $\beta$-actin (catalog \#4331182, ID: Rn00667869_ml) mRNA levels were designed by Applied Biosystems. qPCR was performed on a thermocycler ABI Prism 7500 fast (Applied Biosystems), and the protocol was as follows: (1) $95^{\circ} \mathrm{C}, 10 \mathrm{~min}$; (2) $95^{\circ} \mathrm{C}$, $15 \mathrm{~s}$; (3) $60^{\circ} \mathrm{C}$, and $1 \mathrm{~min}$ (repeat (2) and (3) for 40 cycles). Results were normalized against the internal control using the $\delta$ - $\delta$ CT method.

Western blot. Total protein samples were extracted from hippocampus and prefrontal cortex of rats or primary cultured neurons for immunoblotting analysis. The nuclear protein was extracted using the kit from Beyotime Institute of Biotechnology according to the manufacturer's instructions. Protein concentrations from all extractions were measured using the Bio-Rad Protein Assay (Bio-Rad) in conjunction with bovine serum albumin standards. Protein samples $(60 \mu \mathrm{g})$ were fractionated by SDS-PAGE gel then transferred to PVDF membrane. Anti-BACE1 antibody (catalog \#ab2077; 1:1000; Abcam), anti-APP antibody (catalog \#MAB348-100 $\mu \mathrm{l}$; 1:1000; Millipore), anti-NF $\kappa$ B antibody (catalog \#sc372; 1:200; Santa Cruz Biotechnology), and anti-lamin B antibody (catalog \#sc-6216; Santa Cruz Biotechnology) were used. Western blot bands were captured on the Odyssey Infrared Imaging System (LI-COR Biosciences) and quantified with Odyssey v1.2 software by measuring the band intensity $($ area $\times \mathrm{OD})$ in each group and normalizing to the internal control.

Immunofluorescence detection. Rats were anesthetized with $10 \%$ chloral hydrate $(500 \mathrm{mg} / \mathrm{kg}$, i.p.) and perfused transcardially with $4 \%$ buff- 
ered PFA, pH 7.4. The brains were removed, dehydrated and frozen in OCT, and $20 \mu \mathrm{m} \mathrm{sec}-$ tions were mounted on glass slides. After blocking, sections were incubated with the primary antibodies anti-MAP2 antibody (catalog \#ab11267; 1:200; Abcam), anti-GFAP antibody (catalog \#ab7260; 1:500; Abcam), anti-BACE1 antibody (catalog \#ab2077; 1:1000; Abcam), or antiAPP antibody (catalog \#MAB348-100 $\mu$; 1:1000; Millipore) overnight at $4^{\circ} \mathrm{C}$, and then the brain slices were washed and incubated with the secondary antibodies conjugated to Alexa Fluor 488 and Alexa Fluor 594 (Invitrogen) for $1 \mathrm{~h}$ at room temperature.

Statistical analysis. Data were described as mean \pm SEM. Quadrant-by-quadrant and day-by-day between-group's comparisons were performed using factorial ANOVA (splitplot design). Post hoc analyses of significant main effects were further examined using Fisher's PLSD tests. The two-tailed Student's $t$ test was applied for comparisons between the two groups; $p<0.05$ was considered statistically significant. SAS 9.1 software (Serial number: 989155; Institute Inc.) was used for all statistical analyses.

\section{Results}

Rat model of dementia induced by $\mathrm{CBH}$ generated by $2 \mathrm{VO}$

We developed a rat model of $\mathrm{CBH}$ by $2 \mathrm{VO}$ for 8 weeks to produce the dementia phenotype (Farkas et al., 2007). With the model, we first analyzed cerebral ischemia of rats by TTC staining. The result showed that the $\mathrm{CBH}$ phenotype lasted for at least 8 weeks following $2 \mathrm{VO}$ (Fig. $1 A$ ). Using the MWM test (Vorhees and Williams, 2006), we found that the ability of spatial learning and memory was significantly impaired in $2 \mathrm{VO}$ rats compared with agematched SD rats. First, after guiding a direct path to the hidden platform located in the first quadrant from the second quadrant of the tank, the $2 \mathrm{VO}$ rats had longer latency to navigate to the hidden platform than sham rats after starting from the third and fourth quadrant on day one (Fig. $1 B$; for groups: $F_{(1,17)}=24.55, p<0.0001$; for quadrants: $F_{(2,51)}=$ 19.34, $p<0.0001$; for groups $\times$ quadrants: $F_{(2,51)}=4.91, p=$ 0.0112 ), indicating that $2 \mathrm{VO}$ rats are unable to learn to use cues as navigational guides. Second, in learning trial, the $2 \mathrm{VO}$ rats also took more time to find the hidden platform after they had been released into the tank in all of the three nontarget quadrants day by day (Fig. $1 C-E$; for groups: $F_{(1,17)}=32.67, p<0.0001$; for days $F_{(4,68)}=18.35, p<0.0001$; for groups $\times$ training days: $F_{(4,68)}=$ $0.77, p=0.5477)$. The results suggested that $2 \mathrm{VO}$ rats have the decreased ability to combine cues with memory to reach the target. In addition, in the probe trial, $2 \mathrm{VO}$ rats showed reduced platform crossings $(6.3 \pm 0.29$ and $3.8 \pm 0.23$ times in Sham and 2 VO groups, respectively, $p<0.05$ vs Sham). Further, the percentage of swimming distance in the target quadrant reduced to $\sim 28 \%$ in $2 \mathrm{VO}$ rats from $\sim 34 \%$ in Sham group ( $p<0.05$ vs Sham). These results indicate memory impairment of $2 \mathrm{VO}$ rats compared with Sham group in the probe trial (Fig. $1 F$ ). The decreased microtubule-associated protein 2 (MAP2) and increased glial fibrillary acidic protein (GFAP) expressions were used as hallmarks of dementia induced by cerebral hypoperfusion (Cechetti et al., 2012). In line with this notion, our immunofluorescence staining showed lower MAP2 expression (red) and higher GFAP level (green) in the hippocampus of 2VO rats than that in age-matched sham rats (Fig. $1 G$ ). These changes are consistent with the typical dementia induced by $\mathrm{CBH}$.

Western blot analysis showed that protein levels of APP and BACE1 in the hippocampus and cortex of $2 \mathrm{VO}$ rats were increased by $>1.5$-fold relative to Sham rats (Fig. $2 A$ ). These results were further supported by the increased immunofluorescence densities of both APP (red) and BACE1 (green) in the cortex, CA1, and dentate gyrus (DG) subfield of the hippocampus (Fig. $2 B$ ), though APP mRNAs was not changed nor were BACE1 mRNA levels even decreased in 2VO rats compared with Sham rats (Fig. 2C). In addition, $\mathrm{A} \beta_{40}$ is a more abundant proteolytic product of APP than $\mathrm{A} \beta_{42}$, which is processed by $\gamma$-secretase (Esler and Wolfe, 2001; Jacobsen and Iverfeldt, 2009). In the present study, we found that the soluble $A \beta_{40}$ level in the hippocampus was decreased $23.59 \pm 1.12 \mathrm{pmol} / \mathrm{L}$ in $2 \mathrm{VO}$ rats from $37.59 \pm 3.66 \mathrm{pmol} / \mathrm{L}$ in Sham group rats, but there was no change in its insoluble form between the two groups (Fig. 2D), whereas 

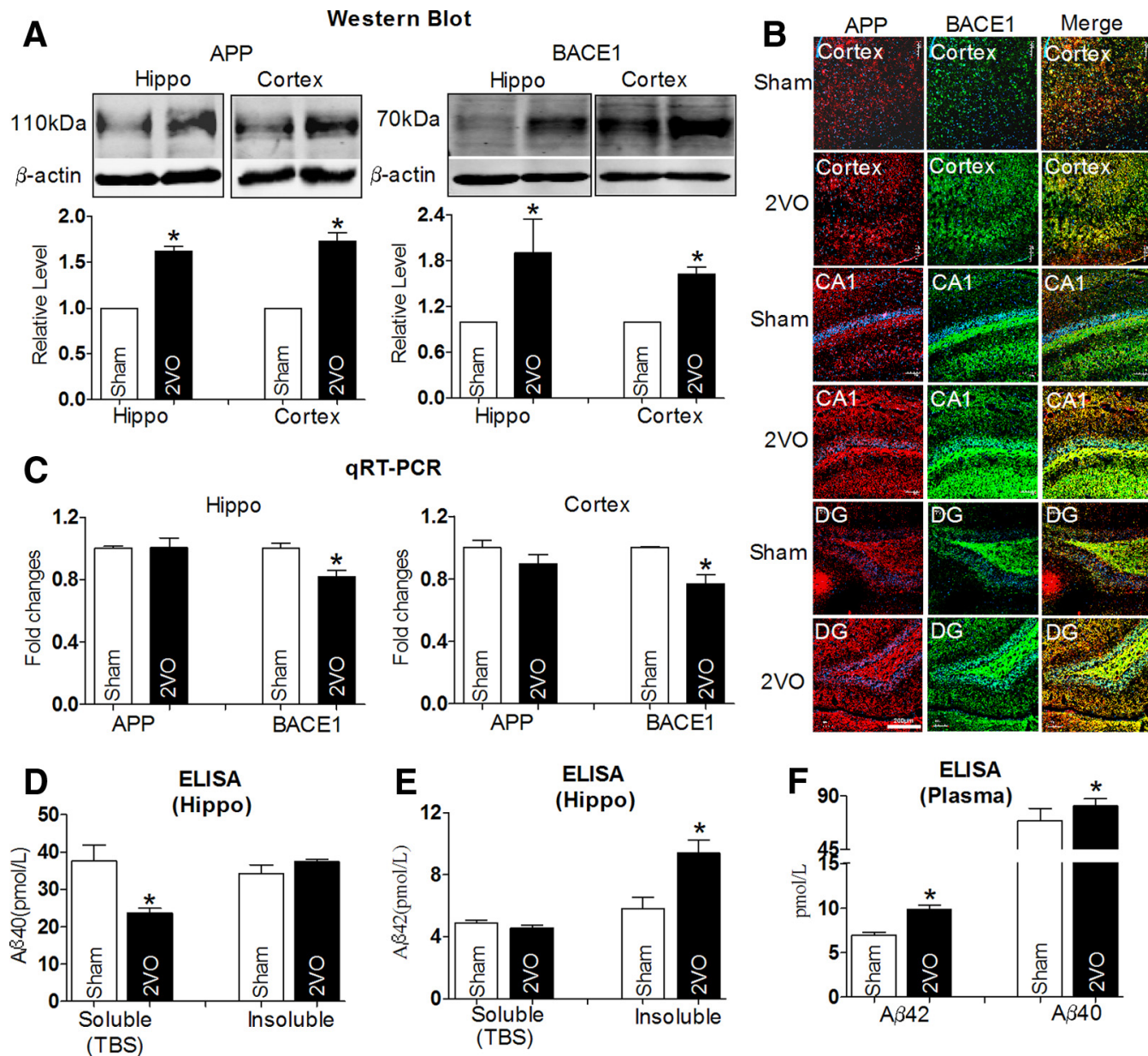

Figure 2. Alterations of APP, BACE1, and A $\beta$ levels in 2 V 0 rats compared with Sham-operated rats. $A$, Western blot analysis with the hippocampus and cortex tissues in Sham and 2 V 0 rats. Top, Representative immunoblotting images of APP, BACE1, and $\beta$-actin. Bottom, The digital data of the immunoblotting analysis. The optical density was evaluated for each band and values for 2 V0 rat tissue were normalized to Sham group after correction for protein loading with $\beta$-actin. ${ }^{*} p<0.05$ versus Sham, $n=6 . \boldsymbol{B}$, Representative confocal microscope images showing cells stained for APP (red, left) and BACE1 (green, middle). Merged images depicting double positivity (yellow) are shown on the right in cortex, CA1, and DG tissues of Sham and $2 \mathrm{VO}$ rats. Scale bar, $200 \mu \mathrm{m}$. C, The relative quantification of APP and BACE1 mRNA levels was detected by qRT-PCR normalized to $\beta$-actin, followed by further normalization to the values from Sham brain tissues. ${ }^{*} p<0.05$ versus Sham, $n=7$. D, Soluble and insoluble $A \beta_{40}$ levels in hippocampus tissues from 2 V0 rats and Sham rats by ELISA assay. ${ }^{*} p<0.05$ versus Sham, $n=5$. E, Soluble and insoluble $A \beta_{42}$ levels in hippocampus tissues from $2 \mathrm{~V} 0$ rats and Sham rats by ELISA assay. ${ }^{*} p<0.05$ versus Sham, $n=7 . F, A \beta_{42}$ and $A \beta_{40}$ levels in plasma of rats by ELISA assay. ${ }^{*} p<0.05$ versus Sham, $n=7$. Hippo, hippocampus.

the total content of $\mathrm{A} \beta_{40}$ in the plasma was significantly increased (Fig. 2F; $69.50 \pm 8.6$ and $81.62 \pm 5.03 \mathrm{pmol} / \mathrm{L}$ in $2 \mathrm{VO}$ and Sham groups, respectively), as determined by ELISA. Since $\mathrm{A} \beta_{42}$ is considered to be a neurotoxic product of endoproteolysis of APP (Rosner et al., 2006), we measured $\mathrm{A} \beta_{42}$ levels in both the hippocampus and plasma. We found that the level of insoluble $\mathrm{A} \beta_{42}$ levels in the hippocampus of $2 \mathrm{VO}$ rats was increased into $9.41 \pm$ $0.41 \mathrm{pmol} / \mathrm{L}$ from $5.83 \pm 0.36 \mathrm{pmol} / \mathrm{L}$ in Sham rats, although its soluble level was unchanged (Fig. 2E). In line with this result, the total $\mathrm{A} \beta_{42}$ level was also increased in plasma of $2 \mathrm{VO}$ rats (Fig. $2 F$ ). Importantly, the ratio of $A \beta_{42} / A \beta_{40}$ was significantly increased in both the hippocampus (soluble: 0.19 ; insoluble: 0.27 ) and plasma $(0.12)$ relative to that in control group (hippocampus: soluble: 0.12 ; insoluble: 0.16 . plasma: 0.09 ). These results suggest that enhanced $\beta$-cleavage of APP may participates in the process of abnormal amyloidogenesis in $2 \mathrm{VO}$ rats (Yin et al., 2007).

\section{MiR-195 targets APP and BACE1}

The fact that the APP and BACE1 protein levels were increased while the mRNA level of APP was unchanged and BACE1 mRNA was even decreased in both the hippocampus and cortex suggests that a post-transcriptional regulatory mechanism might account for the observed changes. To test this notion, we conducted computational analysis using the miRNA databases Targetscan and Pictar to identify the candidate miRNAs that have the potential to regulate the expression of both APP and BACE1. In this way, the miR-195/15b/16 cluster (Fig. 3A) was picked up for our experimental studies. Our qRT-PCR analysis showed that miR-195, a highly conserved transcript among species (Guo et al., 2010), was downregulated into $\sim 60 \%$ of Sham rats in both the hippocampus and the cortex (Fig. 3B), while levels of miR-15b and miR-16 were not significantly changed (Fig. 3C,D). To elucidate whether the decreased miR-195 has potential clinical significance, seven patients who were diagnosed with $\mathrm{VaD}$ according to clinical diagnosis standard were recruited for our study. As illustrated in Figure $3 E$, the plasma concentration of $\mathrm{A} \beta_{42}$ was significantly increased in $\mathrm{VaD}$ patients compared with control group. The $\mathrm{A} \beta_{40}$ level displayed a similar tendency but did not reach statistical significance (Fig. 3E). Further, we found that miR-195 level in blood from $\mathrm{VaD}$ patients was decreased by $\sim 50 \%$ of the control group ( $p<0.05 \mathrm{vs}$ non- $\mathrm{VaD}$ patients, $n=7$ ), indicating that 
miR-195 may also be involved in the pathophysiology of human dementia.

To experimentally verify APP and BACE1 as targets of $m i R-195$, we first cloned the full length of the 3'UTRs of APP or BACE1 containing the $m i R-195$ binding sites into the luciferase-expressing reporter plasmid, and then assessed the effects of miR-195 on reporter activities in HEK293T cells. As shown in Figure $4, A$ and $B$, cotransfection of $m i R-195$ with the plasmid consistently produced less luciferase activities than transfection of the plasmid alone, whereas mutation of the binding sites abolished the effect of miR-195. Application of $2^{\prime}$-O-methyl antisense oligoribonucleotides to $m i R-195$ (AMO-195) eliminated the silencing effect of miR-195 on APP genes (Fig. 4B). There were two binding sites of $m i R-195$ in the 3'UTR of BACE1 (Fig. 4C). As displayed in Figure 4, $D$ and $E, m i R-195$ significantly inhibited luciferase activities of BACE1 (Fig. 4D). Both of the binding sites contributed to the repressive effects. Mutations in the site BACE1-1:266-272 bp and the site BACE1-2:1795-1808 bp reduced the repressive effects on luciferase activities by 20 and $23 \%$, respectively.

To observe whether changes of $m i R$ 195 could affect APP and BACE1 expression in neurons, $m i R-195$ and AMO-195 were transfected by $\mathrm{X}$-treme GENE siRNA transfection reagent into cultured neonatal rat neurons (NRNs). The successful transfection of miR-195 and AMO-195 into NRNs was verified by qRT-PCR (Fig. $5 A$ ). Using immunoblotting and immunofluorescence analyses with cultured NRNs (Fig. 5B-D), we observed that miR-195 effectively inhibited the expression of both APP and BACE1 by nearly $60 \%$ relative to control group, whereas the scrambled NC miRNA failed to affect the protein levels. In contrast, AMO-195 rescued the downregulation of both APP and BACE1 elicited by $m i R-195$, indicating the sequence specificity of $m i R-195$ actions. The mRNA levels of both APP and BACE1 after transfection with miR-195, AMO-195, and miR-195+AMO-195 were unchanged (Fig. 5E). To verify that the observed changes of APP and BACE1 in cultured neurons transfected with $m i R-195$ were the direct actions of $m i R-195$, the miRNA-masking antisense ODNs (miR-masks) technique was used as previously reported (Choi et al., 2007). An miR-mask is an antisense ODN fragment designed to fully base pair to a protein-coding mRNA at the sequence motif spanning the binding site for an endogenous miRNA of interest (Fig. $5 F$ ). Since an miR-mask only acts on the target gene with minimal effects on other target genes that may also be targeted by a same miRNA, the anti-miRNA action of an miR-mask is gene specific. In this study, we designed three $m i R-195$-masks that can base pair the miR-195 binding sites in the $3^{\prime}$ UTRs of APP and BACE1 genes, which are labeled APP-ODN, BACE1-ODN1, and BACE1-ODN2. As expected from their principle of action, these miR-masks, unlike AMO-195, did not affect $m i R-195$ level when cotransfected with $m i R-195$. APP-ODN blocked the repressive effects of $m i R-195$ on APP but did not affect its effects on BACE1 (Fig. 5G). On the other hand, when cells were cotransfected with miR-195 and BACE1-ODN1 or BACE1-ODN2, downregulation of BACE1 by miR-195 was prevented without affecting APP expression (Fig. 5H).

Knockdown of miR-195 elicits learning and memory deficits Upregulation of APP and BACE1 due to miR-195 suppression is expected to promote dementia. To test this notion, $2.0 \mu \mathrm{l}$ of anti-miR-195 oligonucleotide fragment carried by lentivirus vector (lenti-pre-AMO-miR-195) was stereotaxically injected directly into the bilateral hippocampus CA1 subfields for each rat. The injection sites were visualized by Evans blue injection (Fig. $6 A)$. Application of lenti-pre-AMO-miR-195 resulted in significantly lower expression of $m i R-195(>50 \%)$ in the hippocampus of rats after 8 weeks than the rats pre-injected with the NC oligonucleotide (Fig. 6B). In addition, miR-195 downregulation was not limited to the hippocampus, but was also seen in the cortex, suggesting that injected lenti-pre-AMO-miR-195 in the hippocampus can be somehow transferred to the cortex (Fig. 6B). As shown in Figure 6C, by MWM test, loss of function of miR-195 resulted in a prolonged latency to navigate to the hidden platform on day 1 after injection (post hoc analyses, AMO-195 vs NC, Q2: $F_{(2,37)}=1.190, p=0.328 ; \mathrm{Q} 3: F_{(2,37)}=4.499, p<0.05 ; \mathrm{Q} 4:$ $\left.F_{(2,37)}=7.265, p<0.05\right)$, which was partially reversed by combination with lenti-pre-miR-195 (post hoc analyses, AMO-195 vs $\mathrm{AMO}+\operatorname{miR}-195, p<0.05)$. By analyzing the latency to the platform day by day, the lenti-pre-AMO-miR-195 rats took a longer time to find the platform compared with the NC-treated animals, and lenti-pre-miR-195 reversed the prolonged latency to the platform of rats following lenti-pre-AMO-miR-195 injection 
A APP Position 562-568 of APP 3'UTR

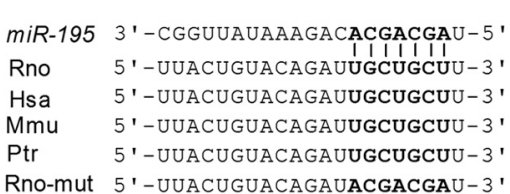

Rno-mut 5' 5'-UUACUGUACAGAUACGACGAU-3'

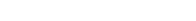

C Bace1 Position 266-272 of BACE1 3'UTR miR-195 3'-CGGUUAUAAAGACACGACGAU-5 ' Rno 5'-UUGG-AAA--UGUUGCUGCUU-3' Hsa 5'-UCGGGAAA--UUCUGCUGCUU-3' Mmu 5'-UUGG-A.AA--UUUUGCUGCUU-3' Ptr 5'-UCGgGaAA--UUCUGCUGCUU-3' Hsa-mut 5'-UUGG-AAA--UGUACGACGAU-3'
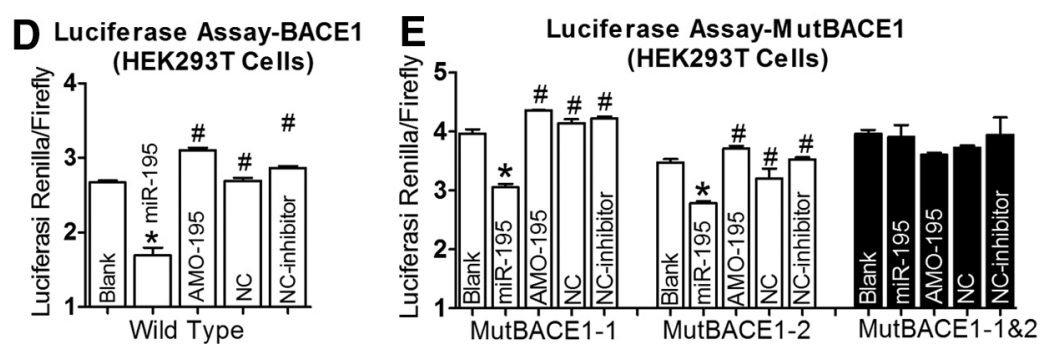

Figure 4. APP and BACE1 are potential targets of miR-195. A, Complementarity between miR-195 seed sequence (5' end 7-8 $\mathrm{nt}$ ) and the $3^{\prime}$ UTR of rat's APP predicted by a computational and bioinformatics-based approach using the Targetscan algorithm. Watson-Crick complementarity is connected by "|". The mutations made to the genes are underlined. $\boldsymbol{B}$, Luciferase reporter gene assay for interactions between miR-195 and its binding sites in the 3'UTR of the APP mRNA in HEK293T cells. Cells were transfected with luciferase-target motif chimeric vector alone, miR-195, miR-195 + AM0-195, or NC using Lipofectamine 2000. ${ }^{*} p<0.05$ versus blank, ${ }^{*} p<0.05$ versus miR-195. C, miR-195 seed sequence ( $5^{\prime}$ end $7-8 \mathrm{nt}$ ) complementary with the $3^{\prime}$ UTR of rat's BACE1 predicted by a computational and bioinformatics-based approach using the Targetscan algorithm. Watson-Crick complementarity is connected by "|". The mutations made to the genes are underlined. $\boldsymbol{D}, \boldsymbol{E}$, Luciferase reporter gene assay for interactions between miR-195 and its binding sites $(\boldsymbol{D})$ or mutation of binding site $(\boldsymbol{E})$ in the ${ }^{\prime}$ UTR of the BACE1 mRNAs in HEK293T cells. Cells were transfected with luciferase-target motif chimeric vector alone, miR-195, miR-195 + AM0-195, or NC using Lipofectamine 2000. ${ }^{*} p<0.05$ versus blank, ${ }^{\#} p<0.05$ versus miR-195.

(Fig. 6D; Day 1: $F_{(4,77)}=6.991, p<0.05$; Day 2: $F_{(4,77)}=6.975$, $p<0.05$; Day 3: $F_{(4,77)}=2.963, p=0.08$; Day 4: $F_{(4,77)}=4.505$, $p<0.05$; Day 5: $\left.F_{(4,77)}=1.530, p=0.24\right)$. Though the lenti-pre$m i R-195$ injection did not reverse the decreased platform crossings induced by the lenti-pre-AMO-miR-195 in probe trial (Fig. $6 E$; crossing times: $8.0 \pm 0.52,4.71 \pm 0.39$, and $6.29 \pm 0.33$ in control; AMO-195; and AMO + miR-195 groups, respectively), the percentage of swimming distance in the target quadrant relative to the total distance was markedly improved from $\sim 30$ to $\sim 35 \%$ (Fig. $6 F$ ). This phenomenon may be caused by the looping search pattern in rats administrated by AMO-195 (Fig. 6G). The protein levels of APP and BACE1 were measured by Western blot. As shown in Figure 6, $H$ and $I$, APP and BACE1 protein levels were significantly increased in both the hippocampus and the cortex in rats treated with lenti-pre-AMO-miR-195, compared with NC group. Cotransfection with the lenti-pre-miR-195 could reverse the effects of AMO-195 (Fig. $6 H, I$ ). The results were further supported by the increase of insoluble $A \beta_{42}$ from the hippocampus after the lenti-pre-AMO-miR-195 injection $(8.45 \pm 0.18 \mathrm{pmol} / \mathrm{L})$, which was reversed by cotransfection with the lenti-pre-miR-195 (5.19 $\pm 0.74 \mathrm{pmol} / \mathrm{L})$, although the soluble $\mathrm{A} \beta_{42}$ levels were not significantly changed among three groups (Fig. $6 \mathrm{~J}$ ). Similar changes of $\mathrm{A} \beta_{42}$ level were observed in blood samples (Fig. $6 K ; 6.98 \pm 0.12,8.53 \pm 0.22$, and $6.85 \pm 0.15$ $\mathrm{pmol} / \mathrm{L}$ in NC; AMO-195; and AMO + miR-195 group, respectively). Importantly, miR-195 effectively reversed the increased ratios of $\mathrm{A} \beta_{42} / \mathrm{A} \beta_{40}$ induced by $\mathrm{AMO}$ 195 in both the hippocampus (Fig. $6 \mathrm{~L}$ ) and plasma (Fig. 6M).

\section{miR-195 mimics mitigate dementia phenotype induced by $2 \mathrm{VO}$}

The next question we asked ourselves was if $m i R-195$ indeed plays a significant role in controlling dementia initiation and maintenance, and if miR-195 is downregulated in the $2 \mathrm{VO}$ dementia model, the overexpression of $m i R-195$ should be able to prevent the dementia phenotype induced by $2 \mathrm{VO}$. To test this hypothesis, lenti-pre-miR-195 was injected into the hippocampus of $2 \mathrm{VO}$ rats. Our data showed that lenti-pre-miR-195 reduced the prolonged latency to locate the platform in $2 \mathrm{VO}$ rats at day 1 (Fig. 7A; Q2: $F_{(2,35)}=0.808, p=0.464 ; \mathrm{Q} 3: F_{(2,35)}=$ 3.947, $p<0.05$; Q4: $\left.F_{(2,35)}=5.301, p<0.05\right)$, significantly improving the memory ability, as indicated by shortened latency to the platform day by day, compared with $2 \mathrm{VO}$ age-matched rats transfected with NC (Fig. 7B; Day 1: $F_{(4,69)}=3.736,12.895$, 7.070, 12.994, 4.656 for Day 1 to Day 5, respectively, $p<0.05)$. In addition, in probe trail, lenti-pre-miR-195 transfection increased the platform crossing times (Fig. 7C) and the percentage of swimming distance in the target quadrant relative to the total distance in $2 \mathrm{VO}$ rats $(\sim 38 \%)$ compared with $2 \mathrm{VO}$ rats treated by $\mathrm{NC}$ (Fig. $7 D, E ; \sim 22 \%$ ).

As predicted, increased APP expression in both the hippocampus and the cortex of $2 \mathrm{VO}$ rats was prevented by lenti-pre- $m i R-195$ transfection (Fig. $7 F$ ). Interestingly, miR-195 inhibited the increased APP and BACE1 expression in the hippocampus induced by $2 \mathrm{VO}$, but did not affected their levels in the cortex (Fig. $7 G$ ). The relative higher expression of $m i R-195$ in the hippocampus than in the cortex of rats after lenti-pre-miR-195 injection might explain the disparate results between APP and BACE1 expression (Fig. 7H). MiR-195 also significantly inhibited the increased insoluble $\mathrm{A} \beta_{42}$ level in the hippocampus (Fig. 7I; insoluble: $5.83 \pm 0.36,9.41 \pm$ $0.41,6.98 \pm 0.23 \mathrm{pmol} / \mathrm{L}$ in $\mathrm{NC}, 2 \mathrm{VO}+\mathrm{NC}$, and $2 \mathrm{VO}+m i R-$ 195 , respectively) and total $\mathrm{A} \beta_{42}$ level in plasma (Fig. 7J; $6.98 \pm$ $0.12,8.98 \pm 0.09,7.54 \pm 0.10 \mathrm{pmol} / \mathrm{L}$ in $\mathrm{NC}, 2 \mathrm{VO}+\mathrm{NC}$, and $2 \mathrm{VO}+m i R-195$, respectively). Thereafter, we found that $m i R$ 195 also effectively mitigated the increased ratios of $\mathrm{A} \beta_{42} / \mathrm{A} \beta_{40}$ in both the hippocampus and plasma induced by $2 \mathrm{VO}$ (Fig. $7 \mathrm{~K}, \mathrm{~L}$ ).

\section{Mechanisms for downregulation of $m i R-195$ in dementia following 2VO}

Having shown that downregulation of $m i R-195$ played a pivotal role in controlling dementia pathology at least partially via regulating expression of APP and BACE1, we went on to elucidate potential molecular mechanisms underlying the deregulation of miR-195 in 2VO rats. Our computational analysis revealed multi$\mathrm{NF} \kappa \mathrm{B}$ binding sites in the promoter domain of the $m i R-195$ gene (Fig. $8 A$ ). Intriguingly, $\mathrm{NF} \kappa \mathrm{B}$ members have been found to contribute to several neurodegenerative disorders, such as $\mathrm{AD}$ and 
Parkinson's and Huntington's disease (Hunot et al., 1997; Kaltschmidt et al., 1997; Khoshnan et al., 2004), and to be activated under anoxia (Sirabella et al., 2009). We therefore examined the possibility of $\mathrm{NF} \kappa \mathrm{B}$ as a regulator of $m i R-195$ transcription.

We found that the promoter sequences of miR-195 are highly conserved between human and rat (Fig. 8A). More important was that there are seven optimal and conserved $\mathrm{NF} \kappa \mathrm{B}$ binding sites in the promoter region of the miR-195 gene (Fig. $8 A$ ). We then tested whether NF $\kappa \mathrm{B}$ could directly bind to the promoter region of miR-195 using ChIP analysis. The data in Figure $8, B$ and $C$, suggest that $\mathrm{NF} \kappa \mathrm{B}$ is able to bind to the $m i R-195$ promoter, and the binding site located in -2000 to -1708 bp upstream of the pre-miR-195 promoter. Next, we evaluated the effect of $\mathrm{NF} \kappa \mathrm{B}$ on $m i R-195$ expression. As shown in Figure 8, $D$ and $E$, the total protein level of $\mathrm{NF} \kappa \mathrm{B}$ did not change in either the hippocampus or the cortex, but it was significantly increased in the nuclear extracts as a proportion of total $\mathrm{NF} \kappa \mathrm{B}$ protein. This finding indicated that $\mathrm{NF} \kappa \mathrm{B}$ may negatively regulate $m i R-195$ expression. In line with our prediction, LPS (an agonist of the p65 subunit of $\mathrm{NF} \kappa \mathrm{B}$ ) significantly inhibited the expression of miR-195 in primary cultured hippocampus neurons (Fig. 8F). As expected, LPS significantly triggered upregulation of both APP and BACE1, an effect abolished by cotransfection with miR-195 (Fig. 8G,H). The results implied that actions of $\mathrm{NF} \kappa \mathrm{B}$ on APP and BACE1 were partially dependent on miR-195.

\section{Discussion}

Together, the present study displayed that downregulation of $m i R-195$ mediated the formation of $\mathrm{A} \beta_{42}$ by upregulating the expression of both APP and BACE1, thereby increasing the susceptibility to dementia of rats following $\mathrm{CBH}$ by $2 \mathrm{VO}$. Another finding is that $\mathrm{NF} \kappa \mathrm{B}$ negatively regulated the expression of $m i R-195$. Therefore, our study revealed a novel insight into the molecular mechanisms of dementia at the miRNA level. Furthermore, our results suggest the possibility of $m i R-195$ as an endogenous anti-dementia miRNA: downregulation of $m i R-195$ can result in an increased vulnerability to dementia.

\section{Consideration of the 2VO animal model}

Senile dementia is a slow developmental process, which results not only from genetic background but also from multi-effectors. Since aggregation of $\mathrm{A} \beta$ (signed by senile plaques), a production of aberrant APP metabolism by BACE1, is considered as a causative factor for dementia, numerous studies focused on the mo-
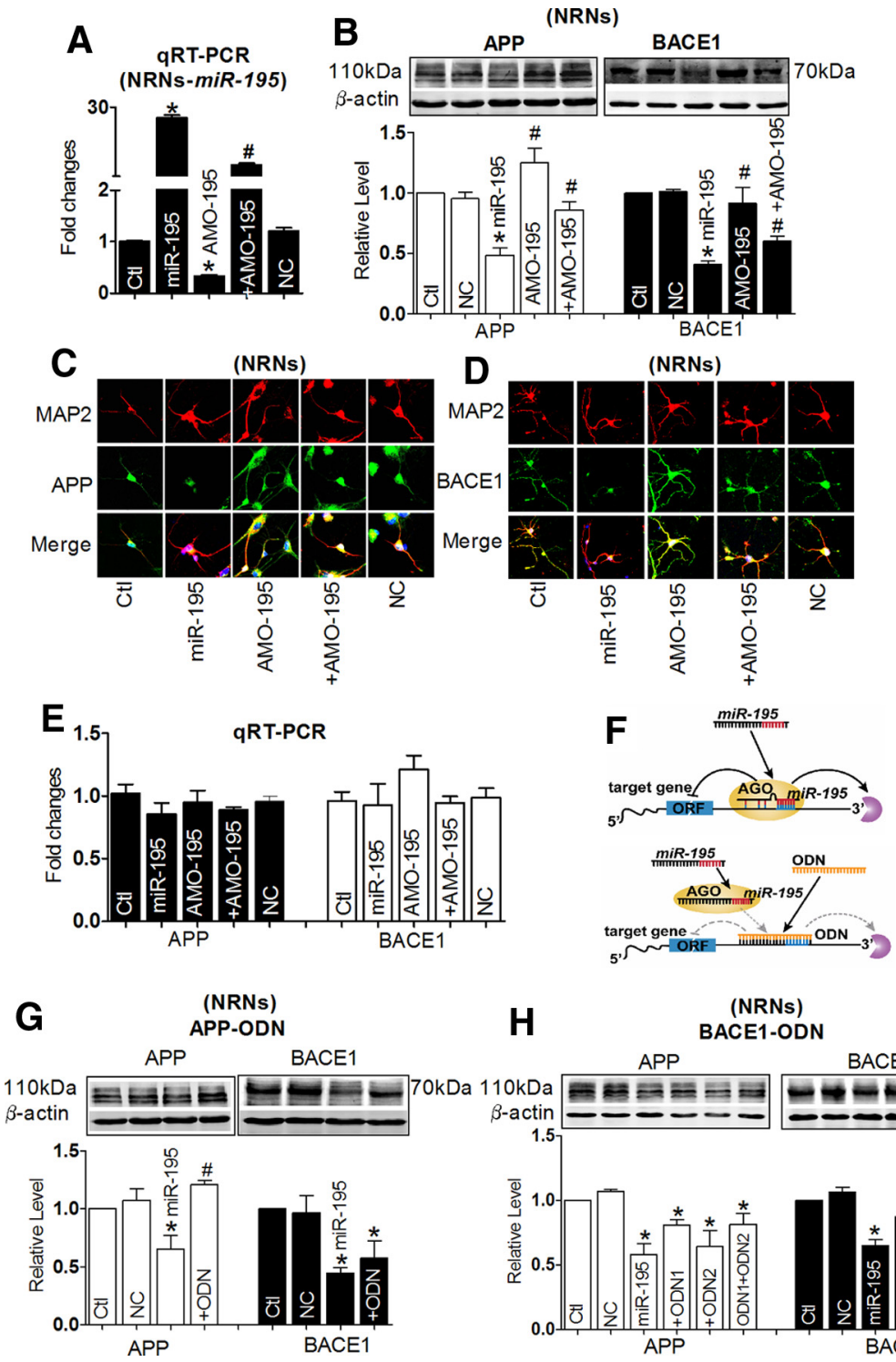

Figure 5. miR-195 downregulates the expression of APP and BACE1 proteins. $\boldsymbol{A}$, Verification of uptake of miR-195 by NRNs after transfection. ${ }^{*} p<0.05$ versus NC, $n=7$ independent RNA samples for each group. $\boldsymbol{B}$, Effects of miR-195 on protein levels of endogenous APP and BACE1 in primary cultured NRNs by Western blot analysis. Cells were transfected with miR-195, AM0-195, miR-195 + AM0-195, or NC, from three batches of cells for each group. ${ }^{*} p<0.05$ versus NC; ${ }^{*} p<0.05$ versus miR-195. C, $\boldsymbol{D}$, Representative confocal microscope images showing primary culture hippocampus neuron stained for MAP2 (red, upper), APP (C, green, middle), and BACE1 ( $\boldsymbol{D}$, green, middle). Merged images depicting double positivity (yellow) are shown on the bottom after transfection with miR-195 mimics and/or AM0-195 and NC. $\boldsymbol{E}$, The mRNA level of APP and BACE1 in cells after transfection with miR-195, AM0-195, and miR-195 + AM0-195. $n=5$. $\boldsymbol{F}$, Schematic of miR-195 silencing using ODNs. Top, miR-195 binds to partially complementary target sites in the $3^{\prime}$ UTRs of target mRNAs (APP and BACE1), which mediates translational repression or mRNA degradation. Bottom, Gene-specific ODNs (designed as 22 oligonucleotides fully complementary to the complete sequence of miR-195 target sites in the 3'UTRs of target mRNAs) with high binding affinity completely masking the target sites of miR-195 in the 3'UTRs of target mRNAs, which block the repression of target mRNAs. ORF, open reading frame; AG0, argonaute. $\boldsymbol{G}, \boldsymbol{H}$, Derepression of APP by APP-ODN $(\boldsymbol{G})$ and BACE1 by BACE1-ODN $(\boldsymbol{H})$ in NRNs, respectively, determined by Western blot analysis. $n=3$ batches of cells for each group. ${ }^{*} p<0.05$ versus NC; ${ }^{\#} p<0.05$ versus miR-195. Ctl, control.

lecular mechanisms of dementia triggered by the $\mathrm{A} \beta$ aggregation in transgenic mice. However, the predisposing factors of the $\mathrm{A} \beta$ aggregation are still poorly understood due to the lack of an ideal animal model that mimics the developmental process of dementia in clinic. There is a consensus that brain hypoxia is a pivotal inducer of dementia. However, acute cerebral infarction after stroke was not suitable to assess the cognitive function due to the severe dyskinesia. A moderate but persistent reduction in brain blood flow, also named chronic brain hypoxia, was reported to 
A
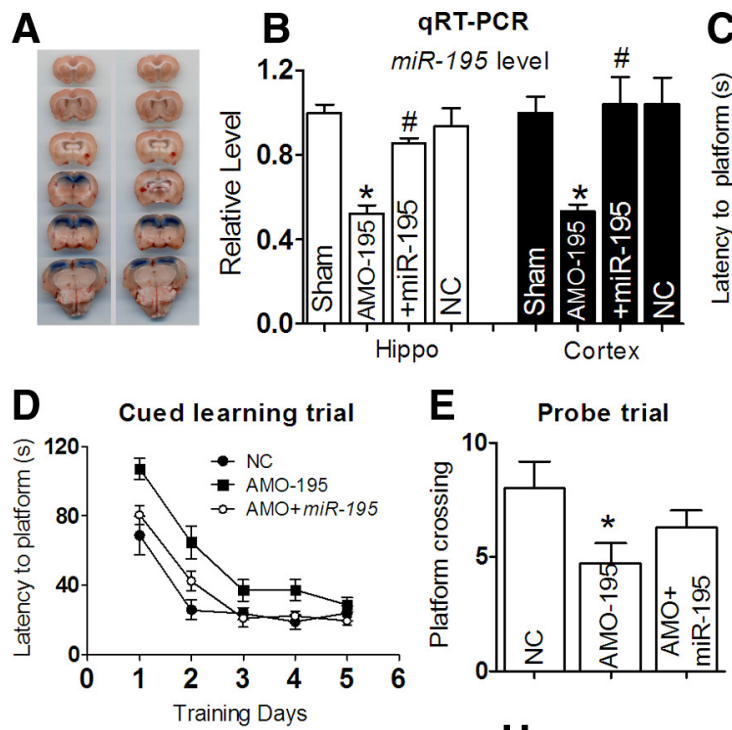

H

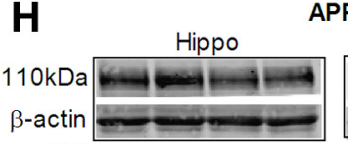

APP
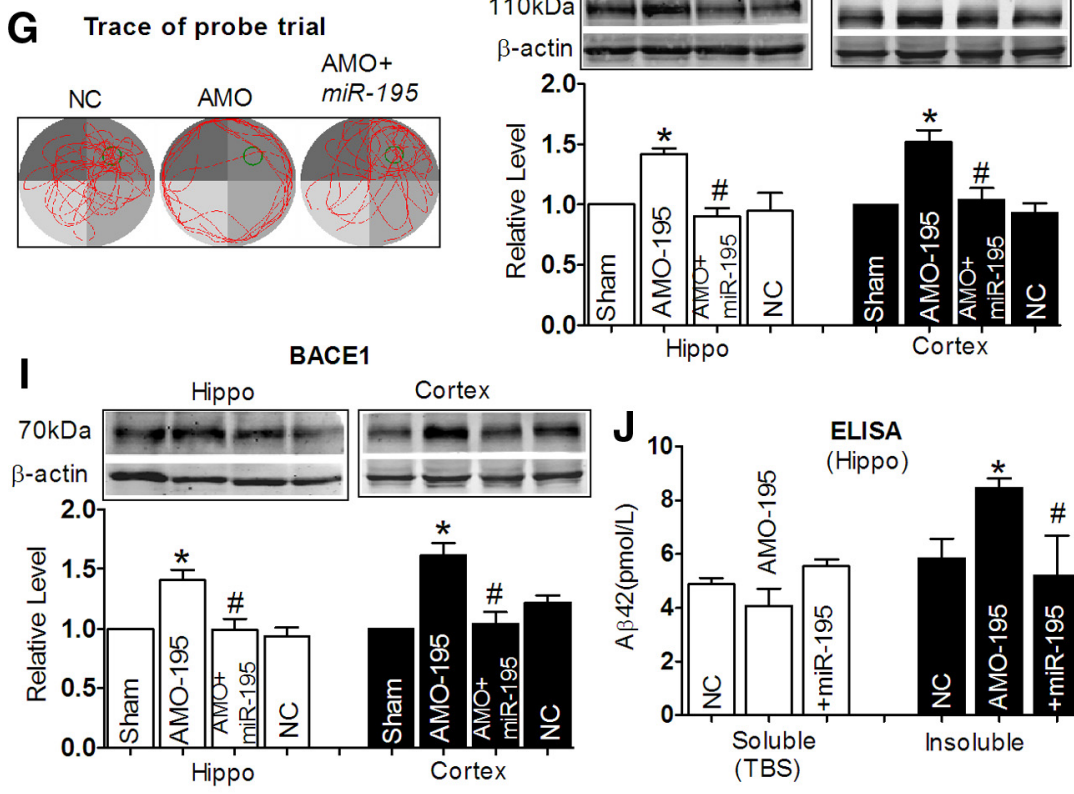

C Cued learning trial

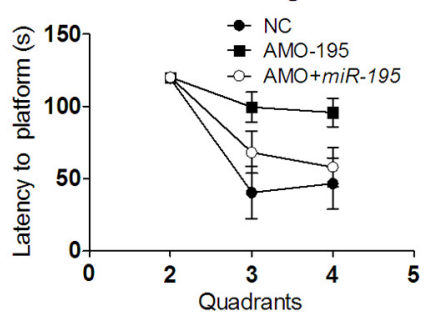

F Probe trial
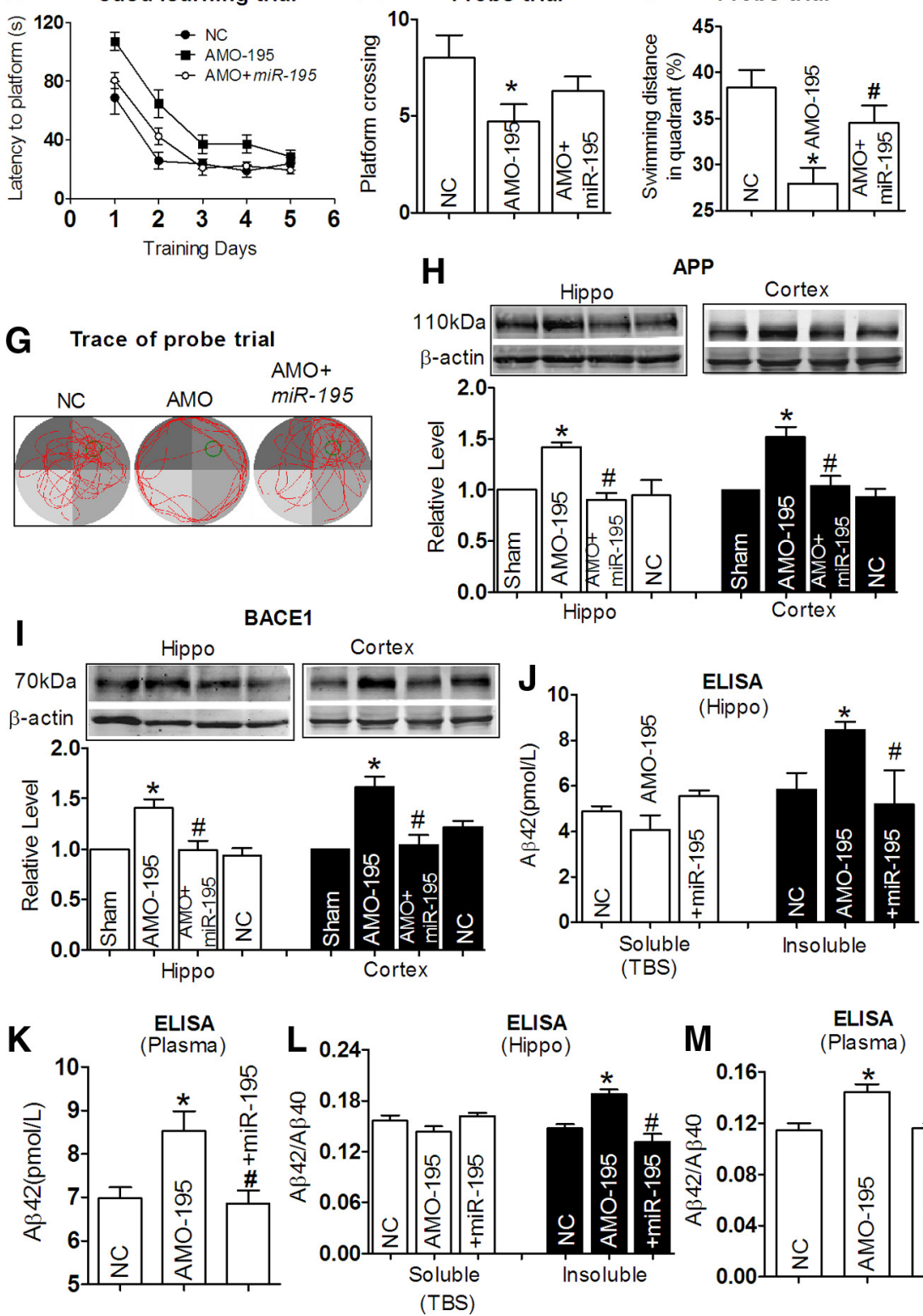

M
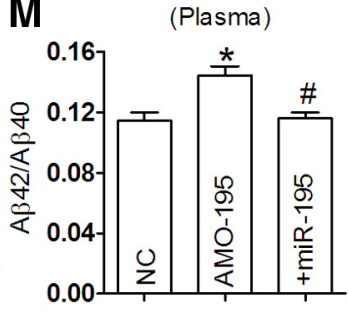

Figure 6. miR-195 knockdown produces learning and memory deficits in rats. $A$, Verification of the injection sites by Evans blue staining in stereotaxic surgery. B, Quantification of miR-195 in the hippocampus and the cortex tissues after stereotaxic injection for 8 weeks using qRT-PCR. Rats were transfected with lenti-pre-AM0-miR-195, lenti-pre-AM0-miR-195 + lenti-pre-miR-195, or NC. Data shown were from six rats for each group. ${ }^{*} p<0.05$ versus NC; ${ }^{*} p<0.05$ versus lenti-pre-AMO-miR-195. C, Average escape latency to platform at day 1 after lenti-pre-AMO-miR-195, lenti-pre-AMO-miR-195 + lenti-pre-miR-195 treatment, and NC. $n=6$ for NC group, $n=8$ for lenti-pre-AMO-miR-195 group, and blank $n=8$ for lenti-pre-AM0-miR-195 + lenti-pre-miR-195 group. D, Mean daily latencies to escape from the start point onto the hidden platform after lenti-pre-AMO-miR-195, lenti-pre-AM0-miR-195 + lenti-pre-miR195 treatment for 8 weeks. $n=6$ for NC group, $n=8$ for lenti-pre-AM0-miR-195 group, and $n=8$ for lenti-pre-AM0-miR-195 + lenti-pre-miR-195 group. E, Number of times crossed the target platform location during probetrial. ${ }^{*} p<0.05$ versus NC, $n=6$.F, Percentage of swimming distance in the target quadrant relative to the total distance of the pool during probe trial. ${ }^{*} p<0.05$ versus NC, $\# p<0.05$ versus lenti-pre-AM0-miR-195, $n=6$. G, Representative path tracings of the probe test on day 6 in the MWM

compromise memory processes and contribute to the development and progression of dementia (Farkas et al., 2007; Gorelick et al., 2011), which better reflects the status of patients suffering from dementia in clinic. Previous studies have documented that $\mathrm{CBH}$ generated by $2 \mathrm{VO}$ can provoke chronic brain hypoxia without motor dysfunction in rats (Sarti et al., 2002a), we therefore used a rat model of $\mathrm{CBH}$ by $2 \mathrm{VO}$ in the present study. Our data showed that $2 \mathrm{VO}$ for 8 weeks in rats not only induced $\mathrm{CBH}$ but also triggered spatial memory impairment without motor dysfunction. The pathophysiological characteristics of $\mathrm{CBH}$ induced by $2 \mathrm{VO}$ were further indicated by the downregulation of MAP2 and upregulation of GFAP. In addition, $2 \mathrm{VO}$ rats displayed spatial memory impairment: the failure to use the cues to learn to find goals in learning trial and the decreased swimming distance in target quadrant in the probe trial. These results demonstrated that $\mathrm{CBH}$ generated by $2 \mathrm{VO}$ for 8 weeks in rats could induce impairment of cognition, which is in line with previous reports (Sarti et al., 2002b; Kumaran et al., 2008). It is worth mentioning that, in the present study, we used SD rats but not Wistar rats to establish the $2 \mathrm{VO}$ animal model due to a greater mortality of Wistar rats after $2 \mathrm{VO}$ than SD rats, which have a relative larger circle of Willis. Basically, $\sim 33-37 \%$ rats were excluded from the experiment due to the loss of pupillary reflex, which was consistent with a previous report (Stevens et al., 2002).

\section{$2 \mathrm{VO}$ produces deposition of $\mathrm{A} \boldsymbol{\beta}$ association with downregulation of $m i R-195$}

Several studies have reported that cerebral hypoperfusion induces dysfunction of metabolism including changes of glucose metabolism, ATPase activity, and the lac-

\footnotetext{
test for each group. $\boldsymbol{H}, \boldsymbol{I}, \mathrm{APP}(\boldsymbol{H})$ and BACE1 $(\boldsymbol{I})$ protein levels in the hippocampus and the cortex tissues after treatment by lenti-pre-AM0-miR-195 and lenti-pre-AM0-miR-195 + lentipre-miR-195 for 8 weeks. ${ }^{*} p<0.05$ versus NC, ${ }^{\#} p<0.05$ versus lenti-pre-AM0-miR-195, $n=6$. J, $A \beta_{42}$ levels in the hippocampus tissues from lenti-pre-AM0-miR-195 and lentipre-AM0-miR-195 + lenti-pre-miR-195 treatment for 8 weeks and from NC rats, measured by ELISA assay. ${ }^{*} p<0.05$ versus NC, ${ }^{\#} p<0.05$ versus lenti-pre-AM0-miR-195, $n=5$. $\boldsymbol{K}$, Elevated $A \beta_{42}$ levels in plasma of rats treated by lenti-preAM0-miR-195 detected by ELISA assay. ${ }^{*} p<0.05$ versus NC, ${ }^{\#} p<0.05$ versus lenti-pre-AM0-miR-195, $n=5$. L, M, The ratios of $A \beta_{42} / A \beta_{40}$ in the hippocampus tissues $(\boldsymbol{L})$ and plasma $(\boldsymbol{M})$ from lenti-pre-AM0-miR-195 and lenti-pre-AM0miR-195 + lenti-pre-miR-195 treatment for 8 weeks and NC rats by ELISA assay, ${ }^{*} p<0.05$ versus NC, $\# p<0.05$ versus lento-pre-AM0-miR-195, $n=5$.
} 
tate concentration, as well as reduced dendritic arborization (Friedrich and Aszódi, 1991; Farkas et al., 2007). Here we observed that $2 \mathrm{VO}$ triggered the $\mathrm{A} \beta$ deposition, which was accompanied by upregulation of both APP and BACE1 proteins, which was consistent with previous reports (Bennett et al., 2000; Zhiyou et al., 2009). Cleavage of APP by BACE1 is the basis for $\mathrm{A} \beta_{42}$ formation, and $\mathrm{A} \beta_{42}$ accumulation is found in most dementias. Since $A \beta$ is not only an initiator of senile plaques but also an inducer of hyperphosphorylated tau protein and neurotoxicity, its accumulation is thought to be an initial causative factor for dementia (Cole and Vassar, 2009). Thus, either preventing the deposition or promoting the clearance of $\mathrm{A} \beta$ may be a rational approach for the treatment of dementia patients (Palop and Mucke, 2010). In the present study, we found that 2VO or AMO-195 injection induced, while upregulation of $m i R-195$ by lenti-pre-miR-195 transfection prevented, the increase of insoluble $\mathrm{A} \beta_{42}$ levels in the hippocampus of rats. In contrast, the soluble $\mathrm{A} \beta_{42}$ levels were not changed. A possible explanation for this observation is that since amyloid formation is a dynamic process, the size of the water-soluble pool will likely fluctuate. Here we are dealing with TBS-soluble $\mathrm{A} \beta_{42}$, which is considered as the $\mathrm{A} \beta_{42}$ secreted to the extracellular environment (Sakono and Zako, 2010). Hence, we speculated that the soluble $\mathrm{A} \beta_{42}$ remained unaltered because it was rapidly incorporated into the insoluble $A \beta$ filaments form, but was not taken up by cells into intracellular pools (as indicated by the lack of appreciable change in the level of RIPA-soluble $\mathrm{A} \beta_{42}$ that was observed; data not shown here). It is worthy of mentioning that the increased ratio of $\mathrm{A} \beta_{42} /$ $\mathrm{A} \beta_{40}$ is considered more crucial than the absolute amount of peptides for induction of neurotoxic conformation (Kuperstein et al., 2010), and a higher ratio of $\mathrm{A} \beta_{42} / \mathrm{A} \beta_{40}$ was demonstrated to be associated with higher BACE1 activities (Yin et al., 2007). Here we found that miR-195 effectively mitigated the increased ratios of $\mathrm{A} \beta_{42} / \mathrm{A} \beta_{40}$ in both the hippocampus and plasma of rats induced by either AMO-195 or $2 \mathrm{VO}$. The results strongly supported that downregulation of $m i R-195$ could induce cognitive impairment associated with abnormal APP processing.

Though the increased expression of BACE1 and APP proteins and their activities were hallmarks in both $\mathrm{AD}$ and $\mathrm{VaD}$ patients, the mRNA level of BACE1 was found unaltered, while that of APP was
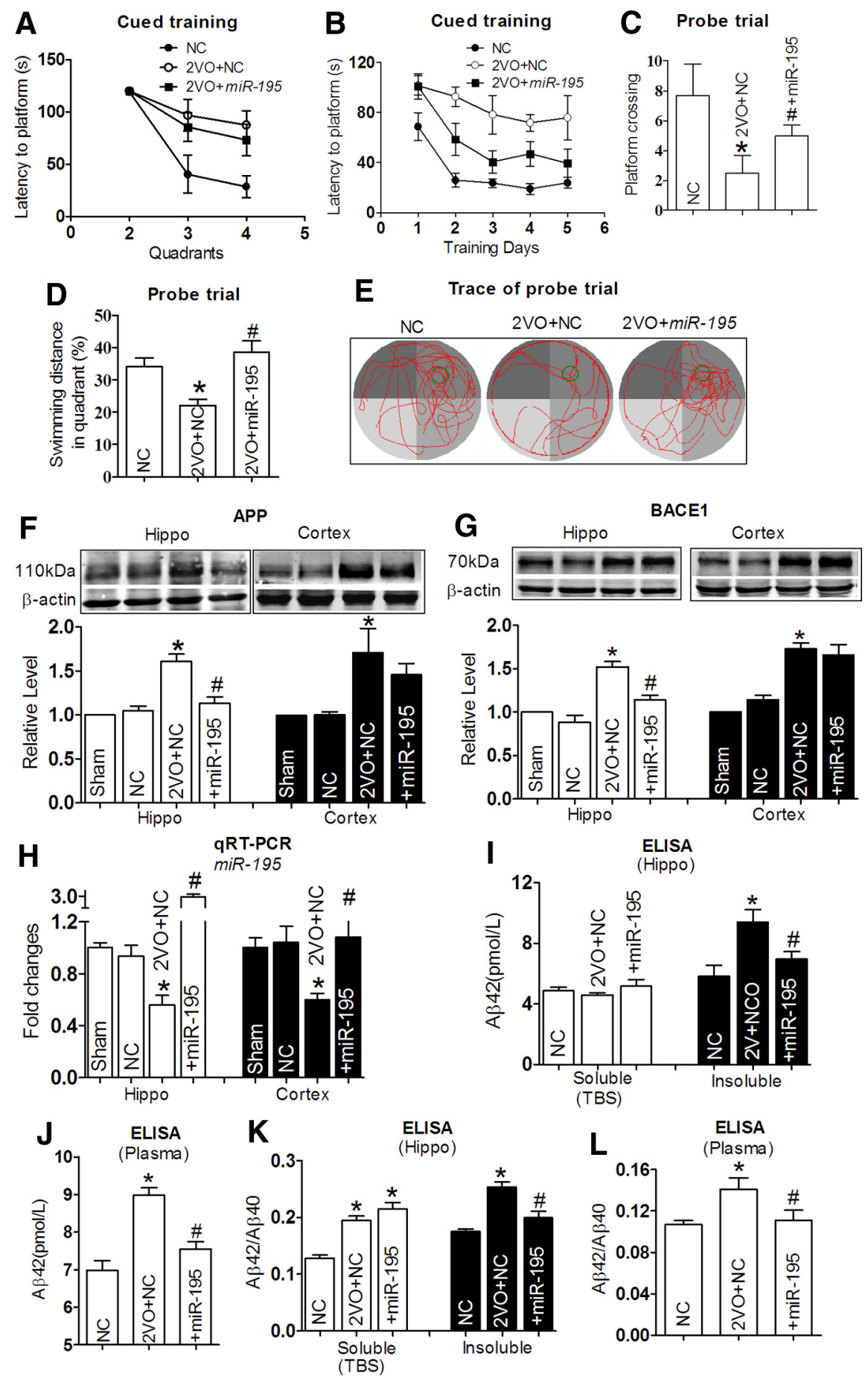

Figure 7. miR-195 attenuates learning and memory deficits in 2V0 model. $\boldsymbol{A}$, Comparison of averaged escape latency to find the platform from three nontarget quadrants at training day 1 after $2 \mathrm{~V} 0$ and $2 \mathrm{~V} 0+$ lenti-pre-miR-195 treatment for 8 weeks. $n=6$. $B$, Mean daily latencies to escape from the start point to the hidden platform after $2 \mathrm{VO}$ and $2 \mathrm{VO}+$ lenti-pre-miR-195 treatment for 8 weeks, $n=6$. C, Number of times crossing the target platform location during probe trial. ${ }^{*} p<0.05$ versus NC, $\# p<0.05$ versus 2V0, $n=6 . D$, Percentage of swimming distance in the target quadrant relative to the total distance during probe trial. * $p<0.05$ versus NC, " $p<0.05$ versus $2 \mathrm{~V} 0, n=6 . \boldsymbol{E}$, Representative path tracings of the probe test on day 6 in the MWM test for each group. Edge-type swim tracing was recorded in 2V0 rats, which was reversed by lenti-pre-miR-195. $\boldsymbol{F}, \mathbf{G}, \mathrm{APP}(\boldsymbol{F})$ and BACE1 (G) protein expression in the hippocampus and the cortex tissues in $2 \mathrm{~V} 0$ rats with or without lenti-pre-miR-195 treatment for 8 weeks. ${ }^{*} p<$ 0.05 versus $N C$, $p<0.05$ versus 2 VO,$n=5$. $\boldsymbol{H}$, Quantification of miR-195 in the hippocampus and cortex tissues of rats 2 VO with or without lenti-pre-miR-195 treatment determined with qRT-PCR. ${ }^{*} p<0.05$ versus NC, ${ }^{\#} p<0.05$ versus 2 V0, $n=5 . I, A \beta_{42}$ levels in hippocampus tissues from 2V0 rats with or without lenti-pre-miR-195 treatment and NC rats by ELISA assay. ${ }^{*} p<0.05$ versus NC, ${ }^{\#} p<0.05$ versus $2 \mathrm{~V} 0, n=5 . J, A \beta_{42}$ levels in plasma by ELISA assay. ${ }^{*} p<0.05$ versus NC, ${ }^{*} p<0.05$ versus 2 V $0, n=$ $5 . \boldsymbol{K}, \boldsymbol{L}$, The ratios of $A \beta_{42} / A \beta_{40}$ in hippocampus tissues $(\boldsymbol{K})$ and plasma $(\boldsymbol{L})$ were compared. ${ }^{*} p<0.05$ versus NC, ${ }^{*} p<0.05$ versus $2 \mathrm{~V} 0, n=5$. 


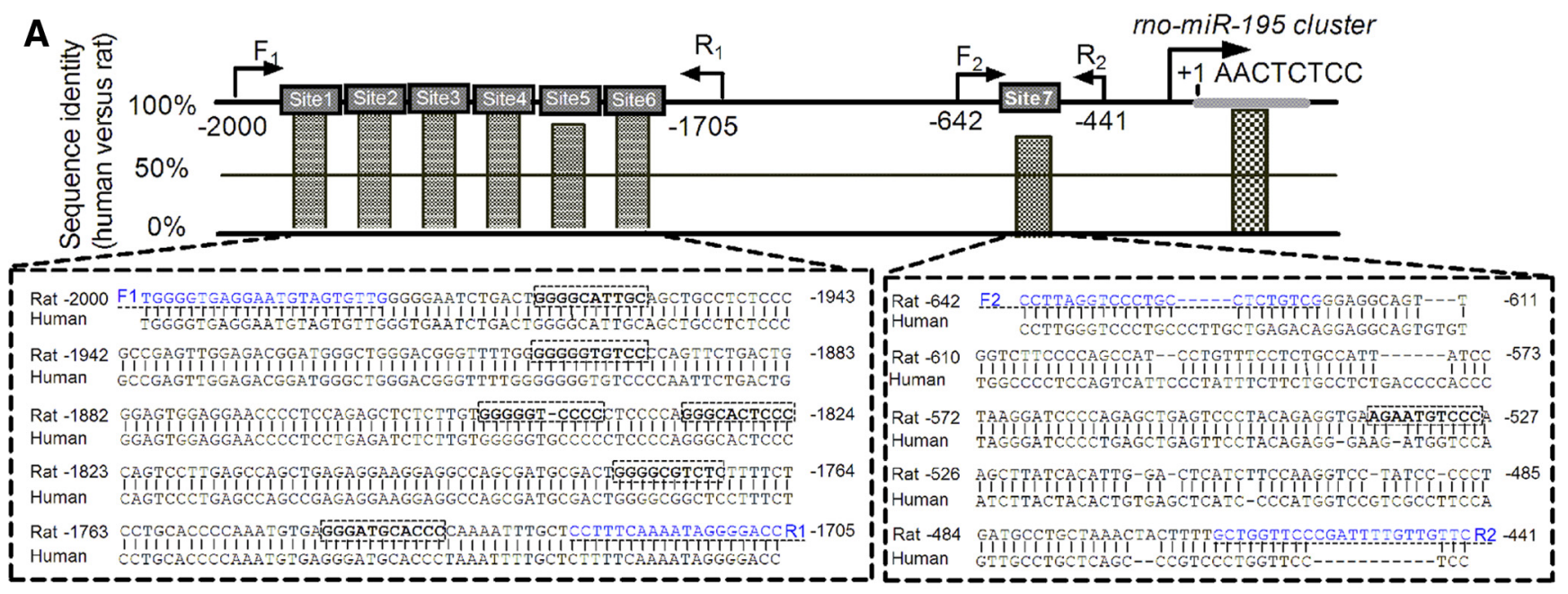

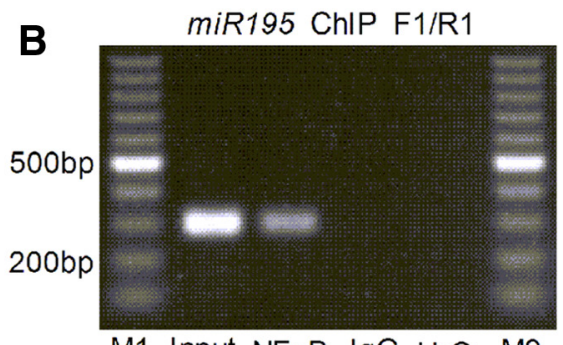

M1 Input $\mathrm{NF}_{\kappa} \mathrm{B} \quad \mathrm{IgG} \mathrm{H}_{2} \mathrm{O} \quad \mathrm{M} 2$
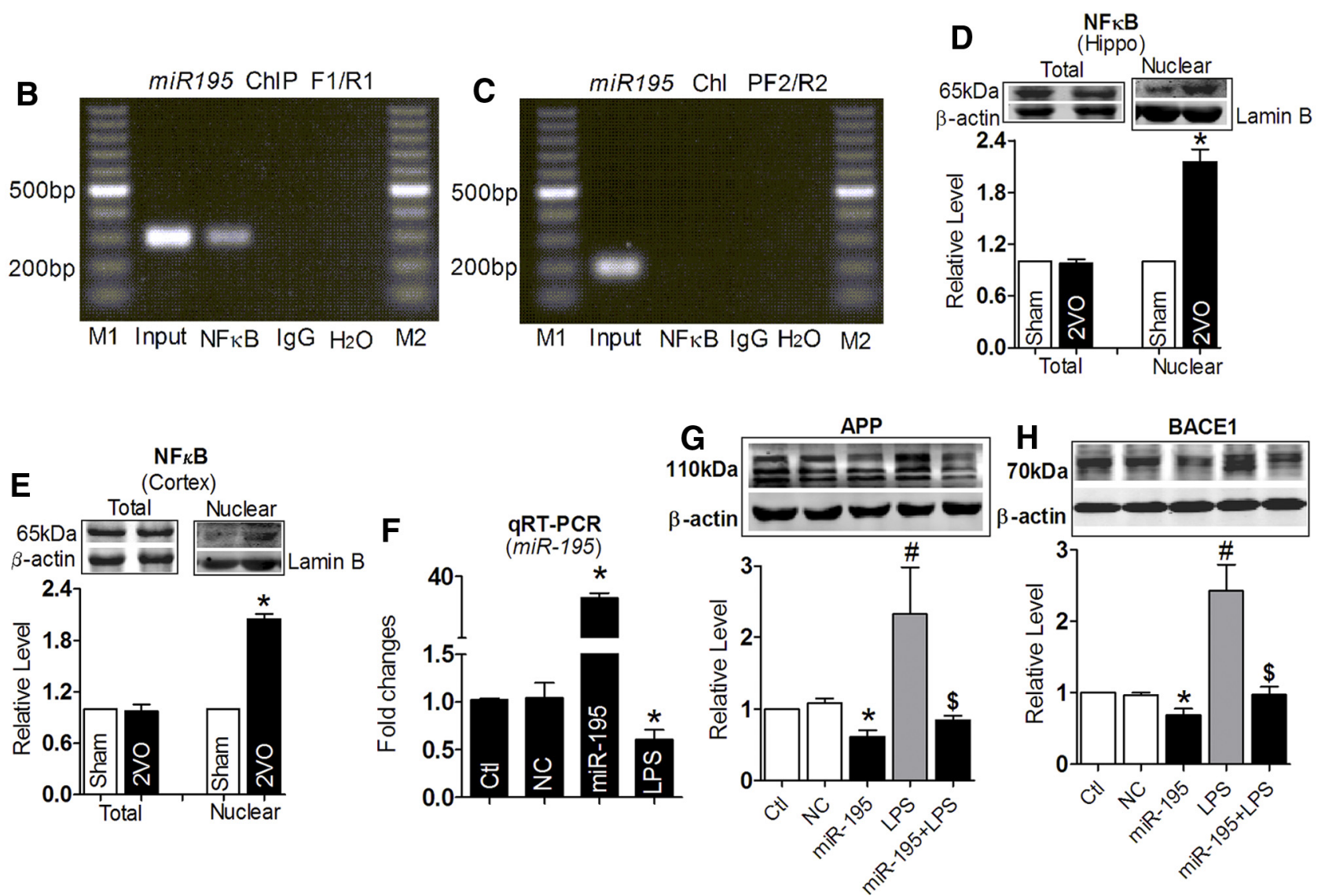

Figure 8. NF $\kappa B$ regulates miR-195 cluster transcription. $A$, Schematic representation of the seven upstream region of the rat $m i R-195$ cluster. Sequences between -2000 and -441 bp of the rat miR-195 cluster are aligned with the corresponding sequences of human miR-195 cluster. The conservative NF $\kappa B$ targeting sites are marked by a box. The primers for $C h I P$ assay were underlined. $B$, ChIP analysis of in vivo $\mathrm{NF} \kappa \mathrm{B}$ binding to the promoter between -2000 and $-1705 \mathrm{bp}$. ChIP assay was performed using hippocampus neuron. The anti-lgG antibody and $\mathrm{H}_{2} 0$ treatment were used as negative control. The anti-NF $\kappa$ B antibody was used to target specific immunoprecipitation. NF $\kappa B$ binding to these target sites activates miR-195 promoter activity. C, ChIP analysis of in vivo NF $\kappa B$ binding to the promoter between -642 and $-441 \mathrm{bp}$. ChIP assay showed that NF $\kappa$ B binding to this target site did not activate miR-195 promoter activity. M1, M2: loading markers; input: positive control. $\boldsymbol{D}, \boldsymbol{E}$, Total and nuclear NF $\kappa$ B protein expression in the hippocampus $(\boldsymbol{D})$ and the cortex $(\boldsymbol{E})$ tissues of $2 \mathrm{~V} 0$ rats. ${ }^{*} p<0.05$ versus Sham, $n=6$. $\boldsymbol{F}$, LPS inhibit the expression of miR-195 determined with qRT-PCR after miR-195 mimics transfection. ${ }^{*} p<0.05$ versus NC, $n=5 . \mathbf{G}, \boldsymbol{H}$, Upregulation of APP ( $\boldsymbol{G}$ ) and BACE1 (H) protein expression induced by LPS, which was reversed by miR-195 mimics transfection. ${ }^{*} p<0.05$ versus NC, ${ }^{\#} p<0.05$ versus miR-195, ${ }^{5} p<0.05$ versus $\mathrm{LPS}, n=5$. Ctl, control.

reduced in the $\mathrm{AD}$ and/or aging brains (Harrison et al., 1994; Preece et al., 2003). In contrast, we found, in the present study, that the level of APP mRNA was unchanged whereas BACE1 mRNA was decreased. These results indicated that posttranscriptional regulation of BACE1 and APP expressions might play a pivotal role under different disease states. A number of putative transcription factor binding sites have been identified in the promoter regions of the BACE1 and APP genes such as $\mathrm{NF} \kappa \mathrm{B}$, Sp1, HNF-3 $\beta$, YY1, MZF1, and GATA in the BACE1 promoter (Rosner et al., 2006), and thyroid hormone (T3), TGF- $\beta 1$, NF $\kappa$ B, and Sp1 in the APP promoter (Amara et al., 1999; Belakavadi et al., 2011). Currently, microRNAs have been commonly consid- 
ered as modulators of protein expression at the posttranscriptional level, modulating the development, function, and pathogenesis in multiple types of diseases. Our findings here disclosed that $\mathrm{miR}-195$, which was able to regulate the expression of both APP and BACE1 genes, was downregulated in both the hippocampus and the cortex of $2 \mathrm{VO}$ rats and in the blood of both $2 \mathrm{VO}$ rats and patients who were diagnosed with $\mathrm{VaD}$ as well, suggesting that downregulated $m i R-195$ might play a role in the initiation and maintenance of dementia induced by $\mathrm{CBH}$. Of note, a recent study reported that, under physiological conditions, $\mathrm{NF} \kappa \mathrm{B}$ triggered a repressive effect on $\mathrm{A} \beta$ production that contributes to maintaining its homeostasis, while participating in a degenerative cycle in which $\mathrm{A} \beta$ would feed its own production under pathological conditions (Chami et al., 2012). Here we found that $\mathrm{NF} \kappa \mathrm{B}$ also regulated the expression of APP and BACE1 indirectly through regulating $m i R-195$ along with its direct action on the APP and BCAE1 transcription (Buggia-Prevot et al., 2008), implying that effect of NF $\kappa \mathrm{B}$ on APP and BACE1 were partially dependent on $m i R-195$ following $\mathrm{CBH}$. In addition, why the BACE1 mRNA level was decreased in rats following $2 \mathrm{VO}$ is unclear, and this needs to be studied further.

\section{MiRNA-195 protects against dementia via its anti- amyloidogenic effect}

Our study provided strong evidence that downregulation of miR-195 in both the hippocampus and the cortex by lenti-preAMO-miR-195 injection could produce susceptibility to dementia due to upregulation of APP and BACE1. In contrast, lenti-pre-miR-195 injection into the hippocampus improved the memory impairment induced by $2 \mathrm{VO}$, which was accompanied by the decreased expression of both APP and BACE1, and the reduced $\mathrm{A} \beta$ depositions as well, though the lost learning ability was not improved. The mechanisms for these observations need to be studied further, yet, the improvement of reduced memory in $2 \mathrm{VO}$ rats after lenti-pre-miR-195 injection suggests that upregulation of $m i R-195$ is a way to prevent dementia associated with $\mathrm{CBH}$.

It is worth mentioning that the $m i R-195$ family harbors many other members including $m i R-15 a b c / 16 / 16 a b c / 322 / 424 / 497 /$ 1907 (http://www.targetscan.org), and previous studies have reported that there are many other miRNAs that can also regulate APP or BACE1 expression. Whether these miRNAs also exert their functions under $\mathrm{CBH}$ conditions is unclear. However, it is intriguing that $m i R-195, m i R-16$, and $m i R-15 b$ seem to independently exert their functions under different disease models, though they are grouped into the same miRNA family. For example, in an age-associated AD animal model (SAMP8), the miR-16 level was significantly decreased with only minor a change of miR-195 level (Liu et al., 2012). In human AD brain, both miR$15 b$ and $m i R-16$ levels were downregulated in white matter with no change of $m i R-195$, while the $m i R-195$ level was decreased in gray matter with no changes of $m i R-15 b$ and $m i R-16$ expression (Wang et al., 2011). In the present study, miR-195 was found decreased whereas $m i R-16$ and $m i R-15 b$ remained unaltered in the $\mathrm{CBH}$ rat model. These results together suggested that miRNAs involved in the same family cluster do not necessarily play a role at the same time and exert the same function.

\section{Limitations and prospects}

In the present study, though we have demonstrated the direct action of $m i R-195$ on the expression of APP and BACE1 using both in vitro and in vivo models, and the promise of $m i R-195$ to prevent dementia induced by $2 \mathrm{VO}$, we cannot exclude other pos- sible mechanisms. Multidisciplinary research has explored various approaches for preventing and/or delaying the onset of latelife dementia (Larson, 2010). There is a great interest in novel therapeutic approaches to treat dementia, one of which in early development is gene therapy (Roshan et al., 2009). Our findings suggest that miR-195 might be a candidate for dementiatargeting gene therapy in the future. However, it should be noted that the data from this study were primarily based upon animal model investigation; caution must be taken when extrapolating the results to humans.

\section{References}

Amara FM, Junaid A, Clough RR, Liang B (1999) TGF-beta(1), regulation of alzheimer amyloid precursor protein mRNA expression in a normal human astrocyte cell line: mRNA stabilization. Brain Res Mol Brain Res 71:42-49. CrossRef Medline

Bales KR, Liu F, Wu S, Lin S, Koger D, DeLong C, Hansen JC, Sullivan PM, Paul SM (2009) Human APOE isoform-dependent effects on brain beta-amyloid levels in PDAPP transgenic mice. J Neurosci 29:6771-6779. CrossRef Medline

Belakavadi M, Dell J, Grover GJ, Fondell JD (2011) Thyroid hormone suppression of beta-amyloid precursor protein gene expression in the brain involves multiple epigenetic regulatory events. Mol Cell Endocrinol 339: 72-80. CrossRef Medline

Bennett SA, Pappas BA, Stevens WD, Davidson CM, Fortin T, Chen J (2000) Cleavage of amyloid precursor protein elicited by chronic cerebral hypoperfusion. Neurobiol Aging 21:207-214. CrossRef Medline

Boissonneault V, Plante I, Rivest S, Provost P (2009) MicroRNA-298 and microRNA-328 regulate expression of mouse beta-amyloid precursor protein-converting enzyme 1. J Biol Chem 284:1971-1981. Medline

Buggia-Prevot V, Sevalle J, Rossner S, Checler F (2008) NFkappaBdependent control of BACE1 promoter transactivation by Abeta42. J Biol Chem 283:10037-10047. CrossRef Medline

Cechetti F, Pagnussat AS, Worm PV, Elsner VR, Ben J, da Costa MS, Mestriner R, Weis SN, Netto CA (2012) Chronic brain hypoperfusion causes early glial activation and neuronal death, and subsequent long-term memory impairment. Brain Res Bull 87:109-116. CrossRef Medline

Chami L, Buggia-Prévot V, Duplan E, Delprete D, Chami M, Peyron JF, Checler F (2012) Nuclear factor-kappaB regulates betaAPP and betaand gamma-secretases differently at physiological and supraphysiological Abeta concentrations. J Biol Chem 287:24573-24584. CrossRef Medline

Choi WY, Giraldez AJ, Schier AF (2007) Target protectors reveal dampening and balancing of Nodal agonist and antagonist by miR-430. Science 318:271-274. CrossRef Medline

Cole SL, Vassar R (2009) Linking vascular disorders and Alzheimer's disease: potential involvement of BACE1. Neurobiol Aging 30:1535-1544. CrossRef Medline

Esler WP, Wolfe MS (2001) A portrait of Alzheimer secretases-new features and familiar faces. Science 293:1449-1454. CrossRef Medline

Farkas E, Luiten PG, Bari F (2007) Permanent, bilateral common carotid artery occlusion in the rat: a model for chronic cerebral hypoperfusionrelated neurodegenerative diseases. Brain Res Rev 54:162-180. CrossRef Medline

Finnerty JR, Wang WX, Hébert SS, Wilfred BR, Mao G, Nelson PT (2010) The miR-15/107 group of microRNA genes: evolutionary biology, cellular functions, and roles in human diseases. J Mol Biol 402:491-509. CrossRef Medline

Friedrich P, Aszódi A (1991) MAP2: a sensitive cross-linker and adjustable spacer in dendritic architecture. FEBS Lett 295:5-9. CrossRef Medline

Gorelick PB, Scuteri A, Black SE, Decarli C, Greenberg SM, Iadecola C, Launer LJ, Laurent S, Lopez OL, Nyenhuis D, Petersen RC, Schneider JA, Tzourio C, Arnett DK, Bennett DA, Chui HC, Higashida RT, Lindquist R, Nilsson PM, Roman GC et al. (2011) Vascular contributions to cognitive impairment and dementia: a statement for healthcare professionals from the American Heart Association/American Stroke Association. Stroke 42:2672-2713. CrossRef Medline

Guo AY, Sun J, Jia P, Zhao Z (2010) A novel microRNA and transcription factor mediated regulatory network in schizophrenia. BMC Syst Biol 4:10. CrossRef Medline

Harrison PJ, Barton AJ, Procter AW, Bowen DM, Pearson RC (1994) The effects of Alzheimer's disease, other dementias, and premortem course on 
beta-amyloid precursor protein messenger RNA in frontal cortex. J Neurochem 62:635-644. Medline

Hébert SS, Horré K, Nicolaï L, Papadopoulou AS, Mandemakers W, Silahtaroglu AN, Kauppinen S, Delacourte A, De Strooper B (2008) Loss of microRNA cluster miR-29a/b-1 in sporadic Alzheimer's disease correlates with increased BACE1/beta-secretase expression. Proc Natl Acad Sci U S A 105:6415-6420. CrossRef Medline

Hébert SS, Horré K, Nicolaï L, Bergmans B, Papadopoulou AS, Delacourte A, De Strooper B (2009) MicroRNA regulation of Alzheimer's amyloid precursor protein expression. Neurobiol Dis 33:422-428. CrossRef Medline

Hunot S, Brugg B, Ricard D, Michel PP, Muriel MP, Ruberg M, Faucheux BA, Agid Y, Hirsch EC (1997) Nuclear translocation of NF-kappaB is increased in dopaminergic neurons of patients with parkinson disease. Proc Natl Acad Sci U S A 94:7531-7536. CrossRef Medline

Jacobsen KT, Iverfeldt K (2009) Amyloid precursor protein and its homologues: a family of proteolysis-dependent receptors. Cell Mol Life Sci 66:2299-2318. CrossRef Medline

Kaltschmidt B, Uherek M, Volk B, Baeuerle PA, Kaltschmidt C (1997) Transcription factor NF-kappaB is activated in primary neurons by amyloid beta peptides and in neurons surrounding early plaques from patients with Alzheimer disease. Proc Natl Acad Sci U S A 94:2642-2647. CrossRef Medline

Khoshnan A, Ko J, Watkin EE, Paige LA, Reinhart PH, Patterson PH (2004) Activation of the IkappaB kinase complex and nuclear factor-kappaB contributes to mutant huntingtin neurotoxicity. J Neurosci 24:7999-8008. CrossRef Medline

Kitaguchi H, Tomimoto H, Ihara M, Shibata M, Uemura K, Kalaria RN, Kihara T, Asada-Utsugi M, Kinoshita A, Takahashi R (2009) Chronic cerebral hypoperfusion accelerates amyloid beta deposition in APPSwInd transgenic mice. Brain Res 1294:202-210. CrossRef Medline

Kumaran D, Udayabanu M, Kumar M, Aneja R, Katyal A (2008) Involvement of angiotensin converting enzyme in cerebral hypoperfusion induced anterograde memory impairment and cholinergic dysfunction in rats. Neuroscience 155:626-639. CrossRef Medline

Kuperstein I, Broersen K, Benilova I, Rozenski J, Jonckheere W, Debulpaep M, Vandersteen A, Segers-Nolten I, Van Der Werf K, Subramaniam V, Braeken D, Callewaert G, Bartic C, D'Hooge R, Martins IC, Rousseau F, Schymkowitz J, De Strooper B (2010) Neurotoxicity of Alzheimer's disease Abeta peptides is induced by small changes in the Abeta 42 to Abeta 40 ratio. EMBO J 29:3408-3420. CrossRef Medline

Larson EB (2010) Prospects for delaying the rising tide of worldwide, latelife dementias. Int Psychogeriatr 8:1196-1202. Medline

Lazarov O, Robinson J, Tang YP, Hairston IS, Korade-Mirnics Z, Lee VM, Hersh LB, Sapolsky RM, Mirnics K, Sisodia SS (2005) Environmental enrichment reduces Abeta levels and amyloid deposition in transgenic mice. Cell 120:701-713. CrossRef Medline

Liu W, Liu C, Zhu J, Shu P, Yin B, Gong Y, Qiang B, Yuan J, Peng X (2012) MicroRNA-16 targets amyloid precursor protein to potentially modulate Alzheimer's-associated pathogenesis in SAMP8 mice. Neurobiol Aging 33:522-534. CrossRef Medline

Long JM, Lahiri DK (2011) MicroRNA-101 downregulates Alzheimer's amyloid-beta precursor protein levels in human cell cultures and is differentially expressed. Biochem Biophys Res Commun 404:889-895. CrossRef Medline

Meilandt WJ, Cisse M, Ho K, Wu T, Esposito LA, Scearce-Levie K, Cheng IH, Yu GQ, Mucke L (2009) Neprilysin overexpression inhibits plaque formation but fails to reduce pathogenic Abeta oligomers and associated cognitive deficits in human amyloid precursor protein transgenic mice. J Neurosci 29:1977-1986. CrossRef Medline

Mellios N, Huang HS, Grigorenko A, Rogaev E, Akbarian S (2008) A set of differentially expressed miRNAs, including miR-30a-5p, act as posttranscriptional inhibitors of BDNF in prefrontal cortex. Hum Mol Genet 17:3030-3042. CrossRef Medline

Palop JJ, Mucke L (2010) Amyloid-beta-induced neuronal dysfunction in Alzheimer's disease: from synapses toward neural networks. Nat Neurosci 13:812-818. CrossRef Medline

Preece P, Virley DJ, Costandi M, Coombes R, Moss SJ, Mudge AW, Jazin E, Cairns NJ (2003) Beta-secretase (BACE) and GSK-3 mRNA levels in Alzheimer's disease. Brain Res Mol Brain Res 116:155-158. CrossRef Medline
Paxinos G, Watson C (1997) The rat brain in stereotaxic coordinates, Ed 3. San Diego: Academic.

Roshan R, Ghosh T, Scaria V, Pillai B (2009) MicroRNAs: novel therapeutic targets in neurodegenerative diseases. Drug Discov Today 14:1123-1129. CrossRef Medline

Rossner S, Sastre M, Bourne K, Lichtenthaler SF (2006) Transcriptional and translational regulation of BACE1 expression-Implications for Alzheimer's disease. Prog Neurobiol 79:95-111. CrossRef Medline

Ruitenberg A, den Heijer T, Bakker SL, van Swieten JC, Koudstaal PJ, Hofman A, Breteler MM (2005) Cerebral hypoperfusion and clinical onset of dementia: the Rotterdam Study. Ann Neurol 57:789-794. CrossRef Medline

Sakono M, Zako T (2010) Amyloid oligomers: formation and toxicity of Abeta oligomers. FEBS J 277:1348-1358. CrossRef Medline

Sarazin M, de Souza LC, Lehéricy S, Dubois B (2012) Clinical and Research Diagnostic Criteria for Alzheimer's Disease. Neuroimaging Clin N Am 22:23-32, viii. CrossRef Medline

Sarti C, Pantoni L, Bartolini L, Inzitari D (2002a) Cognitive impairment and chronic cerebral hypoperfusion: what can be learned from experimental models. J Neurol Sci 203-204:263-266.

Sarti C, Pantoni L, Bartolini L, Inzitari D (2002b) Persistent impairment of gait performances and working memory after bilateral common carotid artery occlusion in the adult Wistar rat. Behav Brain Res 136:13-20. CrossRef Medline

Sirabella R, Secondo A, Pannaccione A, Scorziello A, Valsecchi V, Adornetto A, Bilo L, Di Renzo G, Annunziato L (2009) Anoxia-induced NFkappaB-dependent upregulation of NCX1 contributes to Ca2+ refilling into endoplasmic reticulum in cortical neurons. Stroke 40:922-929. CrossRef Medline

Smith P, Al Hashimi A, Girard J, Delay C, Hébert SS (2011) In vivo regulation of amyloid precursor protein neuronal splicing by microRNAs. J Neurochem 116:240-247. CrossRef Medline

Soon PS, Tacon LJ, Gill AJ, Bambach CP, Sywak MS, Campbell PR, Yeh MW, Wong SG, Clifton-Bligh RJ, Robinson BG, Sidhu SB (2009) miR-195 and miR-483-5p identified as predictors of poor prognosis in adrenocortical cancer. Clin Cancer Res 15:7684-7692. CrossRef Medline

Stevens WD, Fortin T, Pappas BA (2002) Retinal and optic nerve degeneration after chronic carotid ligation: time course and role of light exposure. Stroke 33:1107-1112. CrossRef Medline

Ujifuku K, Mitsutake N, Takakura S, Matsuse M, Saenko V, Suzuki K, Hayashi K, Matsuo T, Kamada K, Nagata I, Yamashita S (2010) miR195, miR-455-3p and miR-10a $\left({ }^{*}\right)$ are implicated in acquired temozolomide resistance in glioblastoma multiforme cells. Cancer Lett 296:241248. CrossRef Medline

Vorhees CV, Williams MT (2006) Morris water maze: procedures for assessing spatial and related forms of learning and memory. Nat Protocols 1:848-858. CrossRef

Wang WX, Rajeev BW, Stromberg AJ, Ren N, Tang G, Huang Q, Rigoutsos I, Nelson PT (2008) The expression of microRNA miR-107 decreases early in Alzheimer's disease and may accelerate disease progression through regulation of beta-site amyloid precursor protein-cleaving enzyme 1. J Neurosci 28:1213-1223. CrossRef Medline

Wang WX, Huang Q, Hu Y, Stromberg AJ, Nelson PT (2011) Patterns of microRNA expression in normal and early Alzheimer's disease human temporal cortex: white matter versus gray matter. Acta Neuropathol 121: 193-205. CrossRef Medline

Xu T, Zhu Y, Xiong Y, Ge YY, Yun JP, Zhuang SM (2009) MicroRNA-195 suppresses tumorigenicity and regulates G1/S transition of human hepatocellular carcinoma cells. Hepatology 50:113-121. CrossRef Medline

Yin YI, Bassit B, Zhu L, Yang X, Wang C, Li YM (2007) \{gamma\}-Secretase Substrate Concentration Modulates the Abeta42/Abeta40 Ratio: implications for Alzheimer disease. J Biol Chem 282:23639-23644. CrossRef Medline

Zhiyou C, Yong Y, Shanquan S, Jun Z, Liangguo H, Ling Y, Jieying L (2009) Upregulation of BACE1 and beta-amyloid protein mediated by chronic cerebral hypoperfusion contributes to cognitive impairment and pathogenesis of Alzheimer's disease. Neurochem Res 34:1226-1235. CrossRef Medline

Zong Y, Wang H, Dong W, Quan X, Zhu H, Xu Y, Huang L, Ma C, Qin C (2011) miR-29c regulates BACE1 protein expression. Brain Res 1395: 108-115. CrossRef Medline 